\title{
Heat transfer coefficients from Newtonian and non-Newtonian fluids flowing in laminar regime in a helical coil
}

\author{
T.A. Pimenta, J.B.L.M. Campos
}

\begin{abstract}
This study aimed to carry out experimental work to obtain, for Newtonian and non-Newtonian fluids, heat transfer coefficients, at constant wall temperature as boundary condition, in fully developed laminar flow inside a helical coil. The Newtonian fluids studied were aqueous solutions of glycerol, $25 \%, 36 \%, 43 \%, 59 \%$ and $78 \%(\mathrm{w} / \mathrm{w})$ and the non-Newtonian fluids aqueous solutions of carboxymethylcellulose (CMC), a polymer, with concentrations $0.1 \%, 0.2 \%, 0.3 \%, 0.4 \%$ and $0.6 \%(\mathrm{w} / \mathrm{w})$ and aqueous solutions of xanthan gum $(\mathrm{XG})$, another polymer, with concentrations $0.1 \%$ and $0.2 \%(\mathrm{w} / \mathrm{w})$. According to the rheological study performed, the polymer solutions had shear thinning behavior and different values of elasticity. The heli- cal coil used has internal diameter, curvature ratio, length and pitch, respectively: $0.004575 \mathrm{~m}, 0.0263$,

$5.0 \mathrm{~m}$ and $11.34 \mathrm{~mm}$. The Nusselt numbers for the CMC solutions are, on average, slightly higher than those for Newtonian fluids, for identical Prandtl and generalized Dean numbers. As outcome, the viscous component of the shear thinning polymer tends to potentiate the mixing effect of the Dean cells. The Nusselt numbers of the XG solutions are significant lower than those of the Newtonian solutions, for identical Prandtl and generalized Dean numbers. Therefore, the elastic component of the polymer tends to diminish the mixing effect of the Dean cells. A global correlation, for Nusselt number as a function of Péclet, generalized Dean and Weissenberg numbers for all Newtonian and non-Newtonian solutions studied, is presented.
\end{abstract}

Keywords

Helical coil, Heat transfer coefficients, Newtonian fluids, Non-Newtonian fluids, Viscoelasticity, Laminar flow

\section{Introduction}

Coiled tubes of helical shape are widely used as heat exchangers and have multiple applications in various industries: chemical, biological, petrochemical, biomedical among others. In these industries, they are applied in a large range of processes, such as: sterilization, pasteurization, concentration, crystallization, separation (distillation) and reaction. They are also found in general purpose equipment: refrigeration, air conditioning and water heating. The fluids involved in these processes may have Newtonian or nonNewtonian behavior.

The helical coils are widely used because they have large heat transfer areas, they are compact, and, above all, their geometry promotes a good mixing of the fluids, increasing the heat and mass transfer coefficients. In addition, this equipment has low cost and is of easy construction and maintenance.

The mixing characteristics are consequence of the development of secondary flows along the tube, the so called Dean effect (Dean
[1]). These secondary flows appear due to the centrifugal force acting on the fluid elements. The difference in axial velocity among the fluid elements flowing in a cross-section leads to a centrifugal gradient. The elements flowing in the center are projected, under the centrifugal force, into the outer wall direction of the coil, where they suffer a decrease of velocity. Afterwards, they return to the center of the tube, forming two, for the case of tubes with a circular cross-section, counter-rotation vortices, the so called Dean cells (Dean [1]). This flow pattern promotes the mixture of the fluid elements. Studies have shown that these secondary flows still have a stabilizing effect on the global flow, promoting a higher critical Reynolds number for transition from laminar to turbulent than that in a straight tube. The secondary flow enhances also the heat transfer in curved pipes in comparison to straight pipes, i.e., the heat transfer coefficients from the coil to the flowing fluid are higher than those in a straight pipe, for the same flow conditions and Prandtl number.

Many authors studied, theoretically and experimentally, heat transfer in coils for Newtonian fluids, among them: Mori and Nakayama [2-4], Schmidt [5], Dravid et al. [6], Akiyama and Cheng [7,8], Tarbell and Samuels [9], Kalb and Seader [10], Olivier and Asghar [11], Janssen and Hoogendoorn [12], Manlapaz and Churchill 


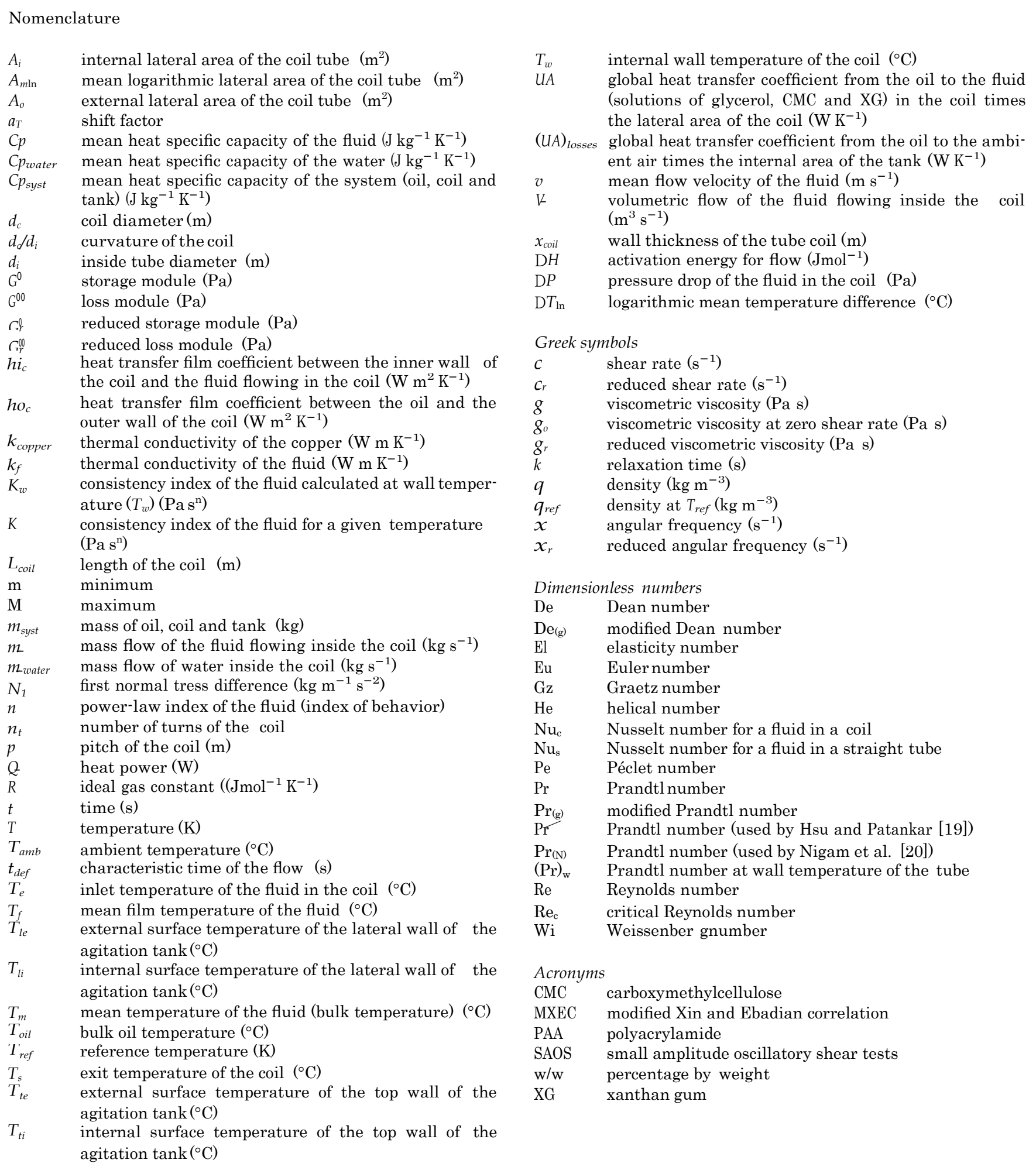

[13], Xin and Ebadian [14] and Jayakumar et al. [15,16]. The great majority of these studies are theoretical, complemented with numerical methods and applied to tubes with zero pitch geometry.

The published studies about heat transfer coefficients for nonNewtonian fluids flowing inside coils are still scarce. From a literature review, we stand out the following works: Rajasekharan et al. [17,18], Olivier and Asghar [11], Hsu and Patankar [19] and Nigam et al. [20]. The majority of these authors concluded that, for the same flow conditions and Prandtl number, shear thinning fluids have smaller heat transfer coefficients than Newtonian fluids, while shear thickening fluids have higher. The study of the elastic effect of the fluids on the heat transfer coefficients in helical coils is still very incipient.

The motivation of the present study is to contribute to the yet incipient study of non-Newtonian fluids, in particular, to the analysis of the elastic effect in the heat transfer coefficients in helical 
Table 1

Literature for Nusselt number correlations applied to Newtonian fluids.

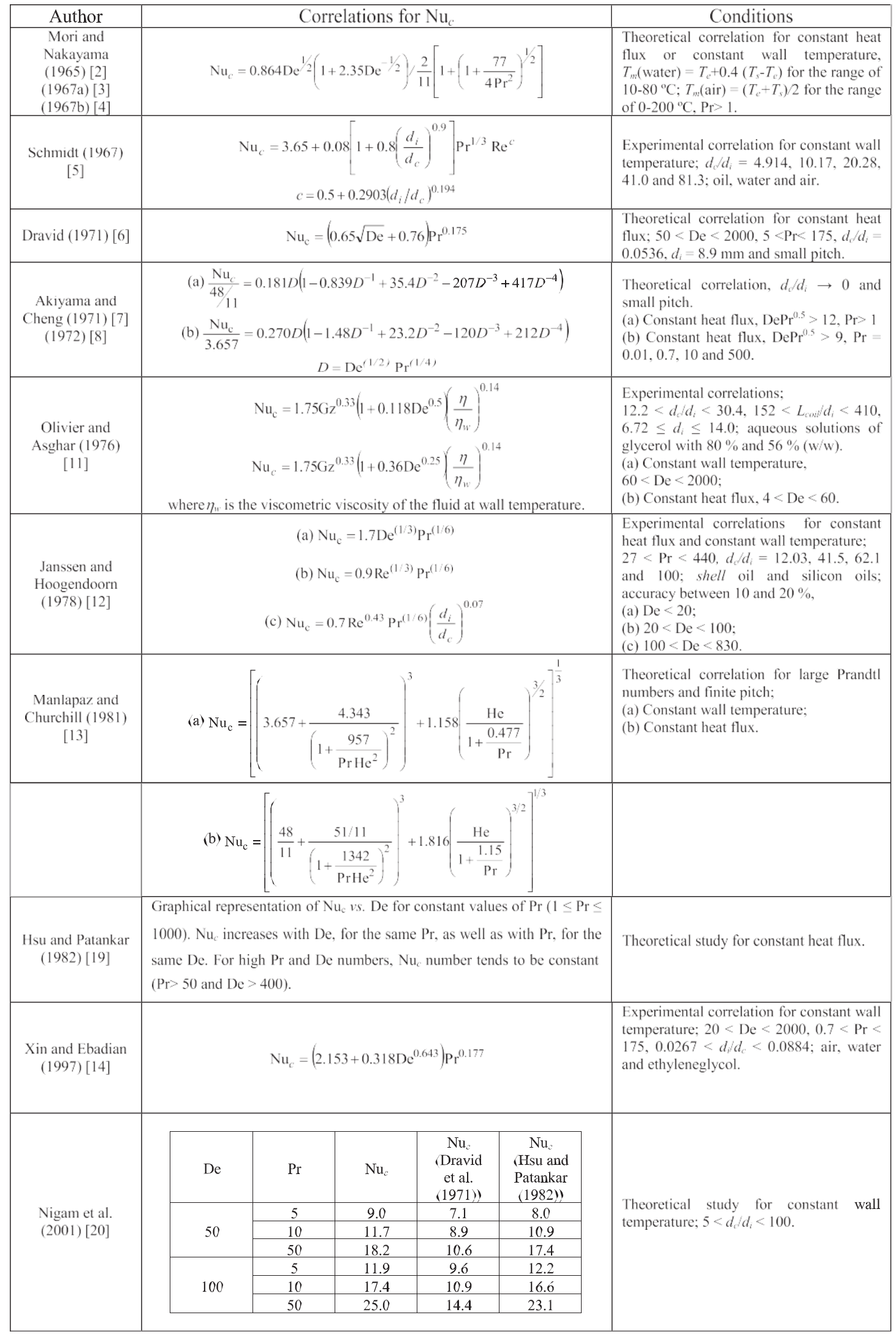




\begin{tabular}{|c|c|c|c|c|c|c|c|}
\hline Author & \multicolumn{6}{|c|}{ Correlations for $\mathrm{Nu}_{\mathrm{c}}$} & Conditions \\
\hline $\begin{array}{l}\text { Rajasekharan et } \\
\text { al. }(1966)[17] \\
\quad(1970)[18]\end{array}$ & \multicolumn{6}{|c|}{$\mathrm{Nu}_{\mathrm{c}}=\left(\frac{3 n+1}{4 n}\right)^{0.7 n}\left(1.98+1.80 \frac{d_{i}}{d_{c}}\right) \mathrm{Gz}^{0.7}$} & $\begin{array}{l}\text { Theoretical correlation for constant wall } \\
\text { temperature; power law fluids (aqueous } \\
\text { solutions), CMC (shear thinning), sodium } \\
\text { silicate (shear thickening), } 0,4<n<2, \\
800<\mathrm{Re}_{\mathrm{g}}<9000,10<\mathrm{Gz}<1000,10< \\
\mathrm{Pr}_{\mathrm{g}}<100 \text {; helical coils and spiral coils, } \\
\text { number of turns between } 5.5 \text { and } 12 \text {, } \\
\text { inside diameter between } 6.5 \text { and } 12.7 \mathrm{~mm} \text {, } \\
0.031<d / d_{c}<0.222 \text {. }\end{array}$ \\
\hline $\begin{array}{c}\text { Olivier and } \\
\text { Asghar (1976) } \\
\text { [11] }\end{array}$ & \multicolumn{6}{|c|}{ 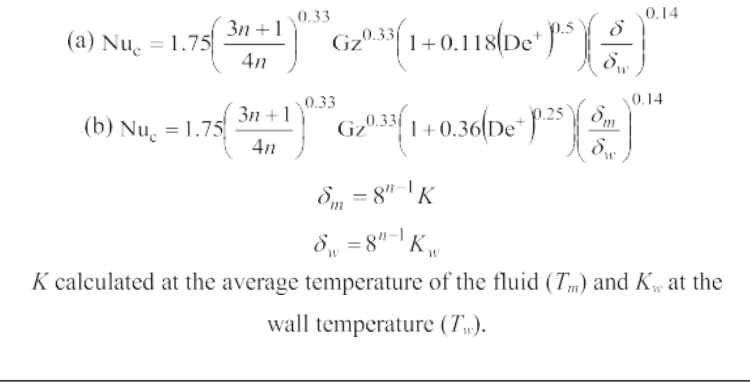 } & $\begin{array}{l}\text { Experimental correlation for constant wall } \\
\text { temperature; viscoelastic fluids (aqueous } \\
\text { solutions) containing PAA, Separan } \\
\text { AP273 and glycerol with } 0.00303<K< \\
0.782 \text { Pas }^{n} \text { and } 0.415<n<0.870 \text {, for the } \\
\text { range } 15-45^{\circ} \mathrm{C} \text {. } \\
\text { Helical coils with } 12.2<d_{i} / d_{i}<30.4,152< \\
L_{\text {coipl }} / d_{i}<410 \text { and } 6.72<d_{i}<14.0 \mathrm{~mm} \text {. } \\
\text { (a) } 60<\mathrm{De}<2000 ; \text { (b) } 4<\mathrm{De}<60 \text {. } \\
\text { The authors found a decrease in } \mathrm{Nu}_{\mathrm{c}} \\
\text { number with an increase of the } \\
\text { concentration of the polymer, for a given } \\
\text { Gz number. }\end{array}$ \\
\hline $\begin{array}{l}\text { Hsu Patankar } \\
(1982)[19]\end{array}$ & \multicolumn{6}{|c|}{$\begin{array}{l}\mathrm{Nu}_{c} \text { versus } \mathrm{De}_{\mathrm{gg}} \text { for different constant values of } \mathrm{Pr}^{*} \text {. The charts are } \\
\text { forn=1, } 0.5,0.75 \text { and } 1.25 \text {. } \mathrm{Nu}_{\mathrm{c}} \text { increases with } \mathrm{De}(\mathrm{g}) \text {, for the same } \mathrm{Pr}^{*} \text {, as } \\
\text { well as with } \mathrm{Pr}^{*} \text {, for the same } \mathrm{De}_{(\mathrm{g})} \text {. For a given } \mathrm{De}_{\mathrm{g}(\mathrm{g})}, \mathrm{Nu}_{\mathrm{c}} \text { increases with } \\
n \text { and for high Prandtl and Dean numbers, there is an approximation of } \\
\text { Nusselt numbers as observed for Newtonian fluids. }\end{array}$} & $\begin{array}{l}\text { Theoretical study for constant heat flux } \\
\text { and power law fluids. }\end{array}$ \\
\hline \multirow{21}{*}{$\begin{array}{l}\text { Nigam et al. } \\
(2001)[20]\end{array}$} & \multirow{5}{*}{0.5} & $\mathrm{De}^{+}$ & $\operatorname{Pr}_{(\mathrm{N})}$ & $\begin{array}{l}\mathrm{Nu}_{\mathrm{c}} \\
\mathrm{Nigam} \text { et } \\
\text { al. }(2001)\end{array}$ & $\begin{array}{l}\mathrm{Nu}_{\mathrm{c}} \\
\mathrm{Hsu} \text { and } \\
\text { Patankar } \\
(1982)\end{array}$ & $\begin{array}{l}\text { Varia } \\
\text { tion } \\
\%\end{array}$ & \multirow{12}{*}{$\begin{array}{l}\text { Theoretical study for constant wall } \\
\text { temperature, power law fluids, pitch zero } \\
\text { and } 5<d_{i} / d_{i}<100 \text {. }\end{array}$} \\
\hline & & \multirow{3}{*}{25} & 5 & 7.25 & 6.64 & 9 & \\
\hline & & & 15 & 8.10 & 7.83 & 3 & \\
\hline & & & 30 & 10.03 & 9.49 & 5 & \\
\hline & & 50 & 5 & 8,30 & 7,58 & 9 & \\
\hline & \multirow{7}{*}{0.75} & \multirow{4}{*}{50} & $\frac{15}{5}$ & $\frac{10.55}{9.23}$ & $\begin{array}{l}9.25 \\
8.75\end{array}$ & $\frac{13}{7}$ & \\
\hline & & & 15 & 11.50 & 10.35 & 10 & \\
\hline & & & 30 & 12.85 & 12.25 & 5 & \\
\hline & & & 50 & 15.60 & 14.85 & 5 & \\
\hline & & \multirow{3}{*}{100} & 5 & 12.05 & 11.25 & 7 & \\
\hline & & & 15 & 14.50 & 12.15 & 18 & \\
\hline & & & 30 & 16.55 & 14.85 & 11 & \\
\hline & \multirow{9}{*}{1.25} & & 50 & 20.22 & 17.10 & 17 & \\
\hline & & \multirow{4}{*}{75} & 5 & 15.90 & 15.39 & 3 & \\
\hline & & & 15 & 22.10 & 21.80 & 1 & \\
\hline & & & 30 & 26.80 & 25.08 & 7 & \\
\hline & & & 50 & 32.20 & 31.21 & 3 & \\
\hline & & \multirow{4}{*}{100} & 5 & 20.95 & 20.52 & 2 & \\
\hline & & & 15 & 24.12 & 23.60 & 2 & \\
\hline & & & 30 & 30.50 & 29.93 & 2 & \\
\hline & & & 50 & 37.20 & 30.37 & 20 & \\
\hline
\end{tabular}

coils. The study concerning Newtonian fluids is to check the experimental set-up and to support, through comparisons at identical experimental conditions, the study of the non-Newtonian fluids. With these proposes, a detail revision of the literature will be done in the following sections.

\subsection{Review for Newtonian fluids}

The present review is particularly incisive in studies with experimental and geometric conditions compatible with those used in the present work. Table 1 presents the Nusselt numbers in coil, $\mathrm{Nu}_{\mathrm{c}}$, correlations and summarizes the conditions and considerations of these studies.

The dimensionless numbers presented in Table 1 are: Reynolds, (Re), Dean, (De), Prandtl, (Pr), Graetz, (Gz), and Helical, (He) numbers, and the respective definitions are listed below:
$\operatorname{Re}=\rho v d_{i} / \eta$

where $\boldsymbol{v}, d_{i}, q$ and $g$ are, respectively, the mean velocity, the inside diameter of the tube of the coil, the density of the fluid and the viscometric viscosity of the fluid;

$\operatorname{De}=\operatorname{Re}\left(d_{i} / d_{c}\right)^{1 / 2}$

where $d_{c}$ is the coil diameter;

$$
\operatorname{Pr}=\frac{C_{p} \eta}{k_{f}}
$$

where $C_{p}$ is the heat capacity and $k_{f}$ the thermal conductivity of the fluid;

$$
\mathrm{Gz}=\frac{\pi \operatorname{RePr} d_{i}}{4 L_{\text {@il }}}=\dot{m} C p /\left(k_{f} L_{\text {cail }}\right)
$$


where $L_{\text {coil }}$ is the length of the coil and $m$ the mass flow of the fluid and the product RePr the Péclet number, Pe;

$$
\mathrm{He}=\operatorname{Re}\left[\frac{d_{i} / d_{c}}{1+\left(\frac{p}{\pi d c}\right)^{2}}\right]^{1 / 2}
$$

where $p$ is the pitch of the coil.

\subsection{Review for non-Newtonian fluids}

The correlations chronologically listed in Table 2 allow the calculation of Nusselt number in coil, $\mathrm{Nu}_{\mathrm{c}}$, for laminar flow and fully developed non-Newtonian fluids, with the viscometric component

following the power law. These studies are, as referred above, scarce.

The dimensionless numbers used in Table 2 are:

- generalized Reynolds number $\left(\operatorname{Re}_{\mathrm{g}}\right)$ (Metzner and Reed [21]):

$\operatorname{Re}_{\mathrm{g}}=\frac{d_{i}^{n} v^{2-n} \rho}{K\left(\frac{1+3 n}{4 n}\right)^{n} 8^{n-1}}$

where $K$ is the consistency index and $n$ the behavior index of the fluid.

Table 3

Dimensions of the helical coil of copper.

\begin{tabular}{ll}
\hline & $\begin{array}{l}\text { Average of the measured } \\
\text { values }\end{array}$ \\
\hline Internal diameter of the coil $(\mathrm{mm})$ & $167.79 \pm 1.21$ \\
External coil diameter $(\mathrm{mm})$ & $179.47 \pm 1.27$ \\
Coil height $(\mathrm{mm})$ & $111.11 \pm 0.85$ \\
Vertical distance between turns $(\mathrm{mm})$ & $4.99 \pm 0.09$ \\
Angle of the turns with the horizontal plane & $3.17 \pm 0.19$ \\
$\quad$ & $4.32 \pm 0.05$ \\
Inside diameter of the tube (mm) & $6.35 \pm 0.05$ \\
External diameter of the tube (mm) & $4.01 \pm 0.03$ \\
Internal diameter of the fittings $(\mathrm{mm})$ & $5.5 \pm 3.79$ \\
Length of the coil tube (m) & 11.34 \\
Coil pitch (mm) & 9.4 \\
Number of turns &
\end{tabular}

- Reynolds number used by Olivier and Asghar [11] $\left(\operatorname{Re}^{+}\right)$:

$\operatorname{Re}^{+}=\frac{d_{i}^{n} v^{2-n} \rho}{K}$

- modified Dean number $\left(\mathrm{De}_{(\mathrm{g})}\right)$ :

$\operatorname{De}_{(g)}=\operatorname{Re}_{g}\left(\frac{d_{i}}{d_{c}}\right)^{0.5}$

- Dean number used by Olivier and Asghar [11] $\left(\mathrm{De}^{+}\right)$:

$D e^{+}=\operatorname{Re}^{+}\left(\frac{d_{i}}{d_{c}}\right)^{0.5}$

- modified Prandtl number $\left(\operatorname{Pr}_{(g)}\right)$ :

$\operatorname{Pr}_{(g)}=\frac{C_{p}}{k_{f}} K\left(\frac{v}{d_{i}}\right)^{n-1}\left(\frac{3 n+1}{4 n}\right)^{n} 8^{n-1}$

- Prandtl number used by Hsu and Patankar [19] $\left(\mathrm{Pr}^{*}\right)$ :

- $\operatorname{Pr}^{*}=\frac{C_{p}}{k_{f}} K\left(\frac{v}{d_{i}}\right)^{n-1}$

- Prandtl number used by Nigam et al. [20] $\left(\operatorname{Pr}_{(\mathrm{N})}\right)$ :

$\operatorname{Pr}_{(\mathbb{N})}=\frac{\rho^{(n-1) /(n-2)} C_{p}\left(\frac{d}{2}\right)^{2(n-1) /(n-2)}}{K^{1 /(n-2)} k_{f}}$

- Péclet number (Pe):

$\mathrm{Pe}=\frac{\rho C_{p} d_{i} v}{k_{f}}=\operatorname{RePr}$

\section{Experimental work}

\subsection{Experimental set-up}

Table 3 presents the dimensions of the copper coil used in this study and the respective uncertainties. Fig. 1 shows a flow diagram of the experimental set-up employed to determine the heat transfer coefficients, for the condition of constant wall temperature. The fluid circulated in a close loop from a first tank, where the temperature was controlled and set constant at $20^{\circ} \mathrm{C}$ by means of a heat pump and a refrigerator, to inside the copper coil. The coil was submerged in a bath of oil mechanically agitated placed in another tank as depicted in Fig. 1. This tank was thermally isolated and

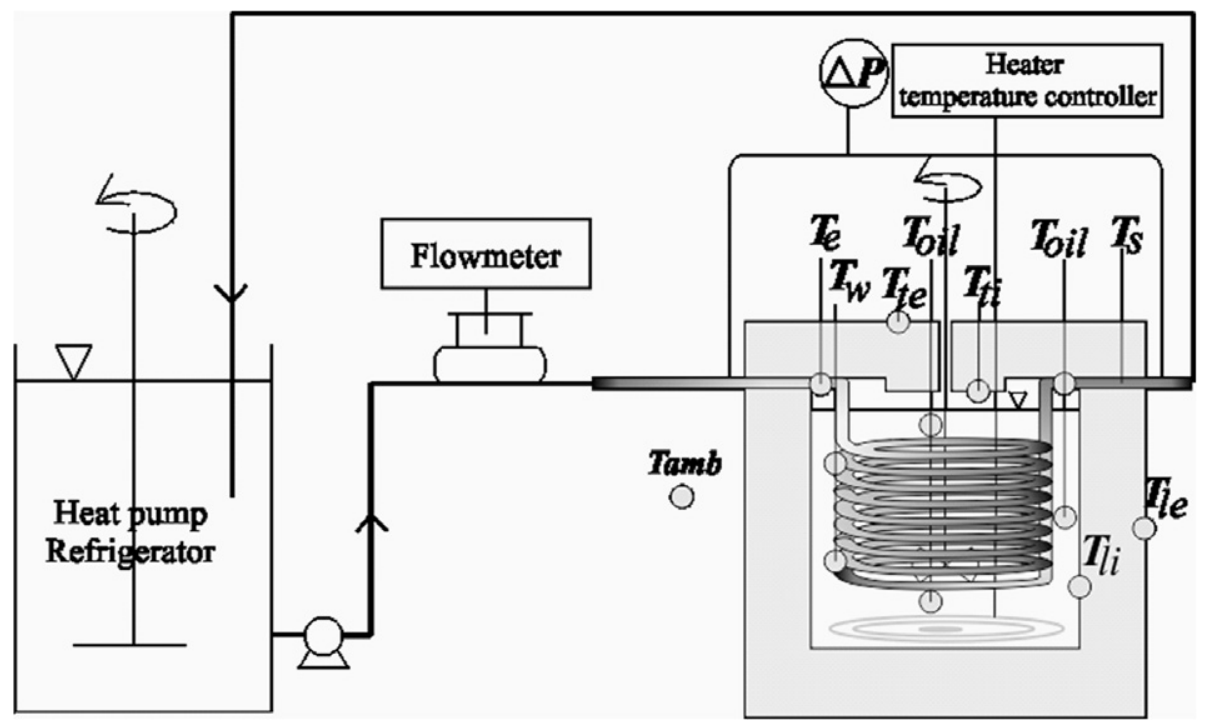

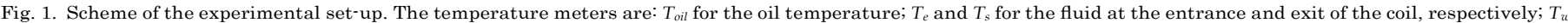

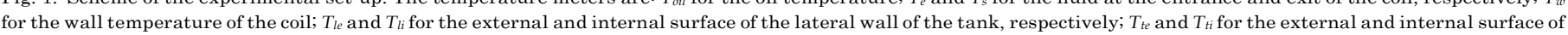

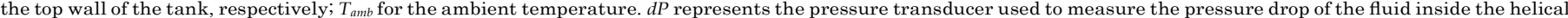

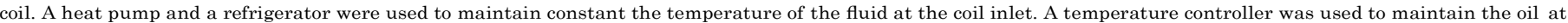
constant temperature. The electromagnetic flowmeter measured the fluid flow rate. 
was provided with a heating system and a temperature controller. The experimental set-up had a centrifugal pump, a transducer to measure the pressure drop of the fluid inside the helical coil (uncertainty $0.028 \%$ full scale (0-6 bar)), an electromagnetic flowmeter (uncertainty of $1.2 \%$ of the volumetric flow), several thermometers T type and Pt100 type (maximum uncertainty of $1.3^{\circ} \mathrm{C}$ ) and two data acquisition systems (a OMEGA PCI 1602 system with 16 bit of resolution for the transducer and electromagnetic flowmeter and a Validyne UPC601-T system with 14 bit of resolution for the temperature meters).

The oil, where the coil was immersed, was a mineral oil used for heat transfer proposes, and it was accompanied by a technical sheet specifying the physical properties.

The heat transfer boundary condition was constant wall temperature $\left(T_{w}\right)$ due to the high rotational velocity of the stirrer $\left(1100 \mathrm{~min}^{-1}\right)$ and, by consequence, to the low heat transfer resistance from the bath to the internal wall of the coil. This boundary condition was validated comparing temperatures measured at the wall of the coil (two positions) and at the oil bath. The relative difference was never higher than $4 \%$.

The experimental rig was validated calculating, with experimental data, both sides of the energy balance equation applied to the cooling of the bath, by water flowing in the coil, in unsteady conditions:

$$
\begin{aligned}
& -\left(m_{\text {syst }} C p_{\text {syst }}\right) \frac{d T_{\text {oll }}}{d t}-(U A)_{\text {lasses }}\left(T_{\text {oll }}-T_{\text {amb }}\right) \\
& =\dot{m}_{\text {water }} C p_{\text {water }}\left(T_{s}-T_{e}\right)
\end{aligned}
$$

where $(U A)_{\text {losses }}\left(T_{\text {oil }}-T_{a m b}\right)$ represents the heatflux lost to the ambient air.

Previously, the global heat transfer coefficient from the oil to the ambient air $\left((U A)_{\text {losses }}\right)$ was experimentally determined, in unsteady state experiments: the oil was heated until a pre-defined temperature and, afterwards, was cooled by the ambient air, i.e., without any cooling fluid flowing inside the coil.

Fig. 2 shows the results of the experimental rig validation.

To obtain the film heat transfer coefficient from the oil to the coil, $h o_{c}=f\left(T_{\text {oil }}\right)$, some experiments were performed, also in unsteady conditions. The experiments were similar to those described above, but, this time, with water at high flow rates flowing inside the coil. In these flow conditions, the dominant thermal resistance was that between the oil and the wall, i.e., any increase in the water flow rate did not induce any effect in the overall heat transfer coefficient. For each experiment, the oil was cooling

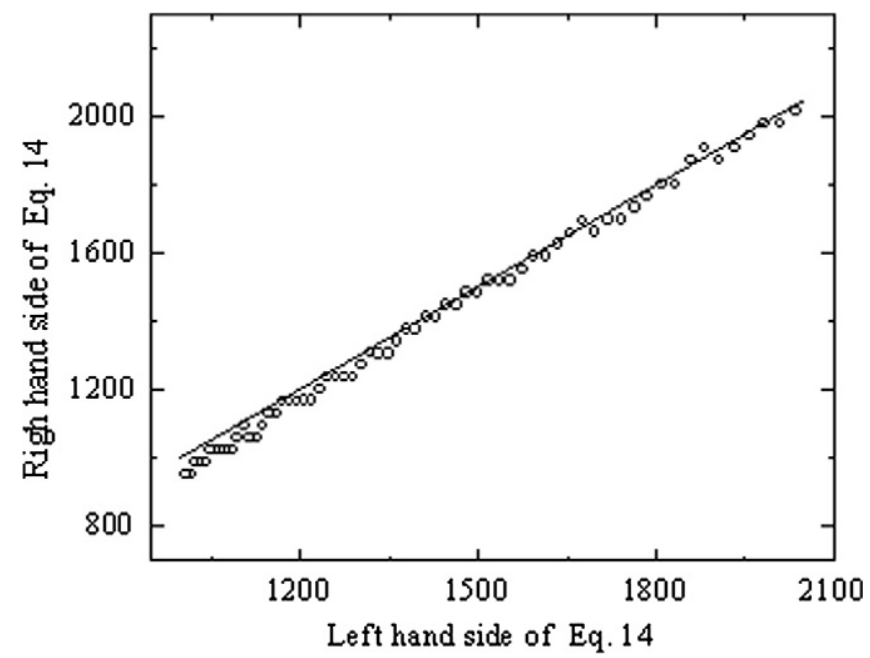

Fig. 2. Results of the experimental energy balance, Eq. (14), for rig validation; the solid line is at $45^{\circ}$. between 80 and $30{ }^{\circ} \mathrm{C}$. The relative uncertainty of these experiments is $4.76 \%$.

\subsection{Characterization of the fluids}

The Newtonian fluids were aqueous solutions of glycerol of $25 \%$, $36 \%, 43 \%, 59 \%$ and $78 \%(\mathrm{w} / \mathrm{w})$ and the non-Newtonian fluids aqueous solutions of carboxymethylcellulose (CMC) of $0.1 \%, 0.2 \%, 0.3 \%$, $1.4 \%$ and $0.6 \%(\mathrm{w} / \mathrm{w})$, with molar mass $3 \times 10^{5} \mathrm{~kg} \mathrm{kmol}^{-1}$ (grade $7 \mathrm{H} 4 \mathrm{C}$ from Hercules), and aqueous solutions of xanthan gum (XG) of $0.1 \%$ and $0.2 \%(\mathrm{w} / \mathrm{w})$, with molar mass $2 \times 10^{6} \mathrm{~kg} \mathrm{kmol}^{-1}$ (grade G1253 from Sigma-Aldrich).The values of the physical properties of the glycerol solutions were obtained in the literature and the viscosity of the solutions was experimentally obtained in a rotational viscometer. The physical properties of the non-Newtonian solutions, except the rheological properties, were taken as identical to those of pure water (Pinho and Coelho [22], Rohsenow et al. [23] and Semmar et al. [24]).

\subsubsection{Rheological characterization of the non-Newtonian fluids}

The viscous and elastic components of the non-Newtonian solutions were characterized in a cutting edge rheometer, trademark PHYSICA model MCR301, and the geometry used was that of cone-plate. The viscometric viscosity was determined, as a function of the shear rate, through steady state shear tests and the elastic component through first normal stress difference, $N_{1}$, and through the loss $\left(G^{0}\right)$ and storage $\left(G^{0}\right)$ modules, these obtained in oscillation tests (small amplitude oscillatory shear tests (SAOS)). For the elastic component, tests in a capillary break-up rheometer, trademark Haake CaBER 1 Thermo Scientific, were also performed.

The rheological tests were performed at $20,25,30,35,40$ and $45^{\circ} \mathrm{C}$, according to the range of the mean temperature $(T)$ of the fluids flowing in the coil. To have additional rheological data, between these temperatures, it was applied the method of reduced variables, described by Bird et al. [25]. In this method, one of the experimental data curve is chosen to be the master curve (data at a temperature designated, from now on, by reference temperature, $T_{r e f}$ ). The factor that allows the overlapping of the other curves with the master curve is called the shift factor, $a_{T}$. For each concentration, this shift factor is function of the temperature and is calculated, supposing negligible effect of the temperature in the density, by:

$$
a_{T}=\frac{\eta_{o}(T) T_{\text {ref }}}{\eta_{o}\left(T_{\text {ref }}\right) T}
$$

where $g_{o}$ is the viscometric viscosity at zero shear rate for temperatures $T$ and $T_{\text {ref, }}$ respectively.

According to Bird et al. [25], the shift factor is related with the temperature by Arrhenius equation:

$a_{\mathrm{T}}=\exp \left[\frac{\Delta H}{R}\left(\frac{1}{T}-\frac{1}{T_{\text {ref }}}\right)\right]$

where $\mathrm{DH}$ is the activation energy and $R$ the ideal gas constant.

According to the reduced variables method, the reduced shear rate, $\mathcal{C}_{r}$, is given by:

$\dot{\gamma}_{r}\left(T_{\text {ref }}\right)=a_{\mathrm{r}} \dot{\gamma}(T)$

and, once more supposing the density of the solutions independent of the temperature, the reduced viscometric viscosity, $g_{r}$, is given by:

$$
\eta_{r}\left(\dot{\gamma}_{r}, T_{\text {ref }}\right)=\frac{\eta(\dot{\gamma}, T) T_{\text {ref }}}{a_{T} T}
$$

According to Metzner and Reed [21], for fluids that follow the power law, the reduced viscometric viscosity is given by: 


$$
\eta_{r}\left(\dot{\gamma}_{r}, T_{\text {ref }}\right)=K\left(\frac{3 n+1}{4 n}\right)^{n}\left(\frac{8 v}{d_{i}} a_{\mathrm{T}}\right)^{n-1}
$$

Figs. 3 and 4 present the master curves and the fitting curves of the power law model, for all solutions of CMC and XG. Fig. 5 shows, for the solution $0.2 \% \mathrm{XG}$, the influence of the temperature on the rheological proprieties according to Arrhenius equation, Eq. (16). According to the figures, the fluids studied exhibit shear thinning behavior. The shear rates values, $v / d_{i}$, of the fluids flowing in the helical coil were in the range where the power law model fits well the experimental data.

Table 4 shows, for all the solutions studied, the power law parameters, $n$ and $K$, for 20 and $40{ }^{\circ} \mathrm{C}$, the shear rate ranges where the parameters are valid and the activation energy values.

The reduced variables method can also be applied to the loss and storage modules:

$$
\begin{aligned}
& \omega_{r}\left(T_{\text {ref }}\right)=a_{T} \omega(T) \\
& G_{r}^{\prime \prime}\left(\omega_{r}, T_{r e f}\right)=G^{\prime}(\omega, T) \frac{T_{r e f}}{T}
\end{aligned}
$$

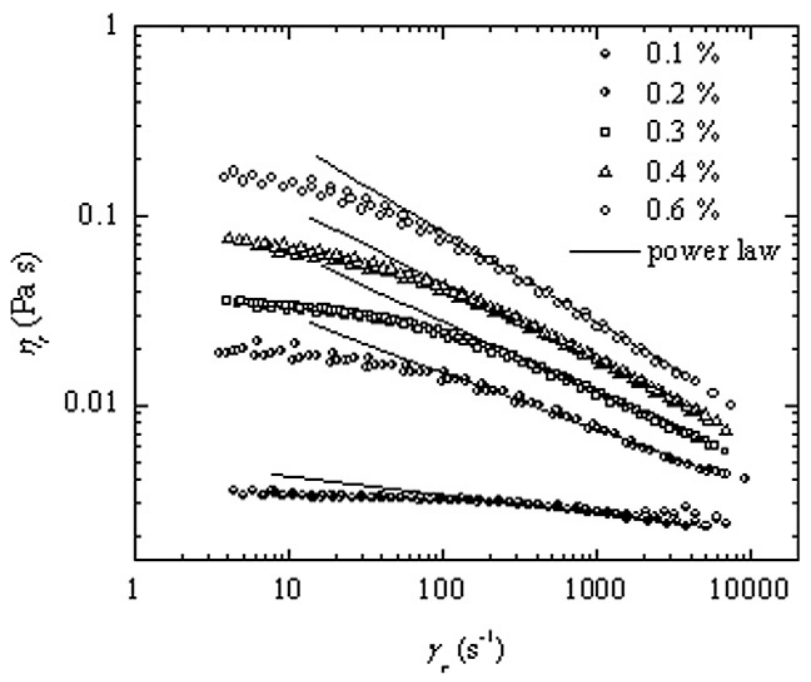

Fig. 3. Reduced viscometric viscosity $\left(g_{r}\right)$ vs. reduced shear rate $\left(\mathcal{C}_{-r}\right)$ (master curves) for solutions $0.1 \%, 0.2 \%, 0.3 \%, 0.4 \%$, and $0.6 \% \mathrm{CMC}$ at $T_{\text {ref }}$ and also the fitting curves of the power law model.

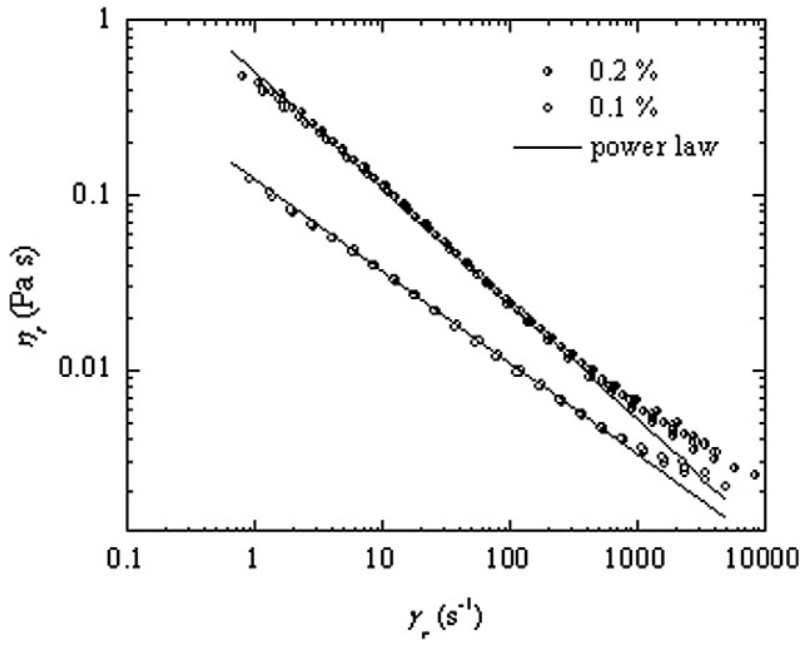

Fig. 4. Reduced viscometric viscosity $\left(g_{r}\right)$ vs. reduced shear rate $\left(c_{r}\right.$ P) (master curves) for solutions 0.1 and $0.2 \% \mathrm{XG}$ at $T_{\text {ref }}$ and also the fitting curves of the power law model.

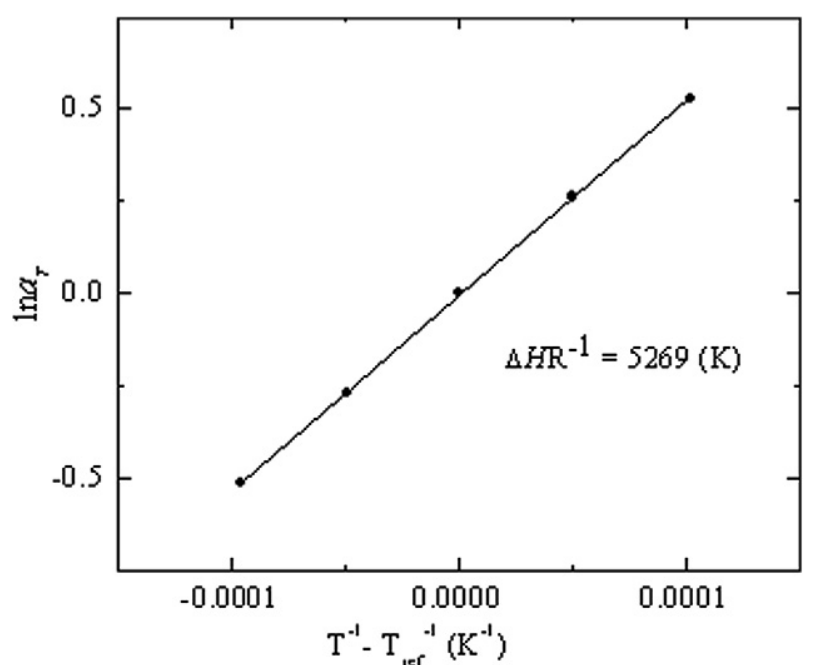

Fig. 5. Influence of the temperature on the rheological proprieties given by Arrhenius equation for $0.2 \%(\mathrm{w} / \mathrm{w}) \mathrm{XG}$ solution (slope $\mathrm{DHR} \mathrm{R}^{-1}$ ).

Table 4

Consistency and behavior indexes and activation energy for the solutions of CMC and XG.

\begin{tabular}{lllllll}
\hline & $\begin{array}{l}\text { Solutions } \\
(\%)(\mathrm{w} / \mathrm{w})\end{array}$ & $\begin{array}{l}\mathrm{Ka} 20^{\circ} \mathrm{C} \\
\left(\mathrm{Pa} \mathrm{s}^{\mathrm{n}}\right)\end{array}$ & $\begin{array}{l}\mathrm{Ka} 40^{\circ} \mathrm{C} \\
\left(\mathrm{Pa} \mathrm{s}^{\mathrm{n}}\right)\end{array}$ & $n$ & $\begin{array}{l}\text { Range of } \mathrm{C} \\
\left(\mathrm{s}^{-1}\right)\end{array}$ & $\begin{array}{l}\mathrm{DHR} \\
(\mathrm{K})\end{array}$ \\
\hline $\mathrm{CMC}$ & 0.1 & 0.008 & 0.004 & 0.90 & $100-2000$ & 2977 \\
& 0.2 & 0.082 & 0.045 & 0.70 & $100-4000$ & 2933 \\
& 0.3 & 0.189 & 0.109 & 0.63 & $300-4000$ & 2956 \\
& 0.4 & 0.376 & 0.227 & 0.58 & $100-4000$ & 3057 \\
& 0.6 & 1.005 & 0.615 & 0.52 & $100-4000$ & 3137 \\
$\mathrm{XG}$ & 0.1 & 0.149 & 0.111 & 0.48 & $2-800$ & 4135 \\
& 0.2 & 0.678 & 0.498 & 0.34 & $2-700$ & 5269 \\
\hline
\end{tabular}

$$
G_{r}^{\prime}\left(\omega_{r}, T_{\text {ref }}\right)=G^{\prime}(\omega, T) \frac{T_{\text {ref }}}{T}
$$

Figs. 6 and 7 show the evolution of the reduced storage module, $G_{r}^{0}$, and of the reduced loss module, $G_{r}^{00}$, with the reduced angular frequency, $x_{r}$, for $0.4 \%(\mathrm{w} / \mathrm{w}) \mathrm{CMC}$ and $0.2 \%(\mathrm{w} / \mathrm{w})$ XG solutions and also measurement equipment limits (baselines).

The relaxation time of the fluid, $\mathrm{k}$, was the parameter used, in this work, to compare the elastic component of the fluids. The

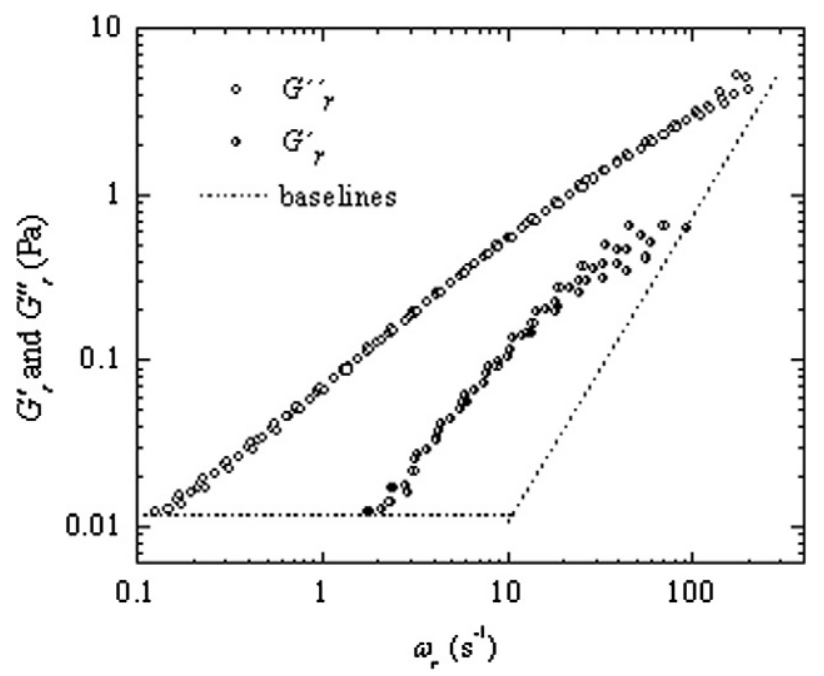

Fig. 6. Reduced loss $\left(G^{00}{ }_{r}\right)$ and reduced storage $\left(G_{r}^{0}\right)$ modules vs. reduced angular frequency $\left(\boldsymbol{x}_{r}\right)$ from oscillatory tests, for the solution $0.4 \%(\mathrm{w} / \mathrm{w})$ CMC at $T_{r e f}$ 


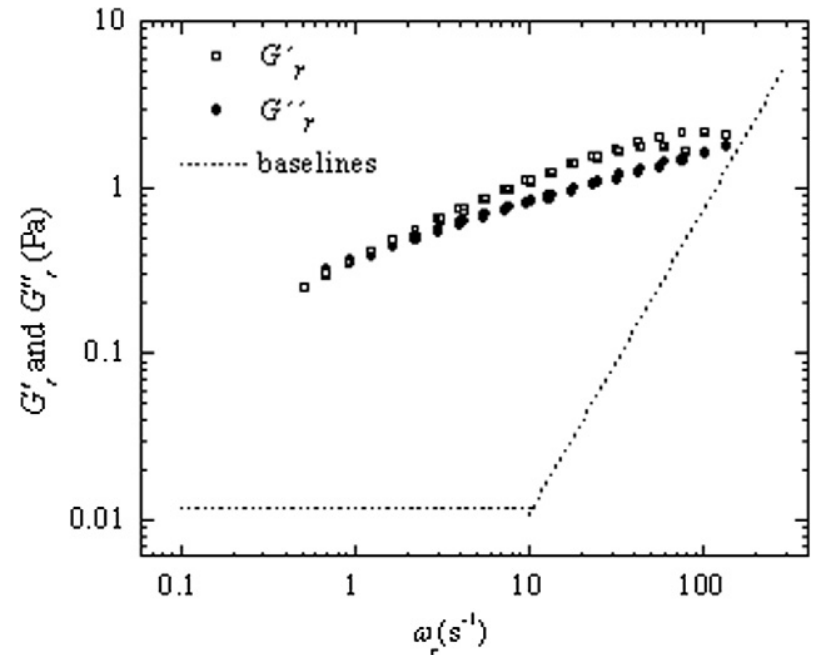

Fig. 7. Reduced loss $\left(G^{00}\right)$ and reduced storage $\left(G^{0}\right)$ modules vs. reduced angular frequency $\left(\boldsymbol{X}_{r}\right)$, from oscillatory tests, for the solution $0.2 \% \mathrm{XG}$ at $T_{r e f}$.

relaxation time allows the calculation of the Weissenberg dimensionless number, Wi, which represents the ratio between elastic and viscous forces:

$$
\mathrm{Wi}=\frac{\lambda v}{d_{i}}
$$

Oscillation tests, in small amplitude oscillatory shear mode (SAOS), were performed to obtain $\mathrm{G}^{0}$ and $\mathrm{G}^{00}$. To obtain the relaxation time, it was followed the approach described by Bird et al. [25], where:

$$
\lambda=\lim _{\omega \rightarrow 0} \frac{G^{\prime} / \omega}{G^{\prime \prime}}
$$

In this approach, $\mathrm{G}^{0}$ and $\mathrm{G}^{00}$ are fitted, with $\mathrm{N}$ modes, according to the Maxwell model. This model combines the viscous and the elastic components of the fluid. The relaxation time is obtained from:

$$
\begin{aligned}
& \lambda=\sum_{k=1}^{N} \frac{\eta_{k} \lambda_{k}}{\eta_{p}} \\
& \text { where } \\
& \eta_{p}=\sum_{k=1}^{N} \eta_{k}
\end{aligned}
$$

where $g_{k}$ and $k_{k}$ are the viscosity coefficient and the relaxation time, respectively, of the Maxwell model.

The relaxation time was also determined using the first normal stress difference, $N_{1}$. The equation used was that of Bird et al. [25]:

$$
\lambda=\lim _{j \rightarrow 0} \frac{N_{1} / \dot{\gamma}^{2}}{2 \eta(\dot{\gamma})}
$$

Table 5 shows the relaxation times, obtained in this work, by

\begin{tabular}{|c|c|c|c|c|c|c|c|}
\hline & $\mathrm{CMC}$ & & & & & $\mathrm{XG}$ & \\
\hline Solutions $(\%)(\mathrm{w} / \mathrm{w})$ & 0.1 & 0.2 & 0.3 & 0.4 & 0.6 & 0.1 & 0.2 \\
\hline $\begin{array}{l}\text { Relaxation time } k(\mathrm{~ms}) \\
\quad(\text { SAOS })\end{array}$ & - & 170 & 340 & 475 & 1086 & 2500 & 4400 \\
\hline $\begin{array}{l}\text { Relaxation time } k(\mathrm{~ms}) \\
\quad(\mathrm{CaBER})\end{array}$ & 4.7 & 4.9 & 5.1 & 8.9 & 16.0 & 12.5 & 26.0 \\
\hline $\begin{array}{l}\text { Relaxation time } k(\mathrm{~ms}) \\
\text { Coelho and Pinho [26] }\end{array}$ & 64 & 162 & 346 & 488 & - & - & - \\
\hline
\end{tabular}
oscillation tests (DAUS) and capillary preak-up tests (UaBEK), both approaches described in Bird et al. 25]. It was found from those methods that the relaxation time increases with the concentration

l'able b

Relaxation time for $\mathrm{CMC}$ and $\mathrm{XG}$ solutions at $25^{\circ} \mathrm{C}$. of the solutions. Furthermore the relaxation times obtained with CaBER method are between 30 and 200 times lower than those obtained by SAOS method. Coelho and Pinho [26] used the same carboxymethylcellulose (CMC) with identical solute concentrations, $0.1 \%, 0.2 \%, 0.3 \%$ and $0.4 \%(\mathrm{w} / \mathrm{w})$ and performed creep tests to determine the relaxation times. Comparing their results with the present results obtained by SAOS method (Table 5), it can be observed a good accordance. Like Cavadas et al. [27] it was found a large dispersion on results of the first normal stress difference $\left(N_{1}\right)$.

\subsection{Experimental conditions}

The value of the critical Reynolds number, $\operatorname{Re}_{\mathrm{c}}$, used to define the transition from laminar to turbulent regime inside the coil was 6240 , according to Ito [28].

Table 6 shows the ranges of Reynolds, Dean, Prandtl and Helical numbers for the different glycerol solutions studied. For all the conditions, the minimum $(\mathrm{m})$ and maximum $(\mathrm{M})$ heat fluxes between the oil and the flowing glycerol solutions were, respectively, 67 and $130 \mathrm{~kW} \mathrm{~m}^{-2}$.

For the CMC and XG solutions, the range of the generalized Reynolds, $\operatorname{Re}_{\mathrm{g}}$, modified Dean, De $(\mathrm{g})$, modified Prandtl, $\operatorname{Pr}_{(\mathrm{g})}$, Prandtl, Pr, (used by Hsu and Patankar [19]), Péclet, Pe, Graetz, Gz, and Wissenberg, Wi, numbers are presented in Tables 7 and 8. Also, in Tables 7 and 8, it is represented the elasticity number, El, which is the ratio between Weissenberg and Reynolds numbers. The elastic number gives the ratio between elastic and inertial forces and it is constant for a given fluid and geometry, when the density and the viscometric viscosity of the solutions are independent of the temperature The Weissenberg number was calculated with the
relaxation time obtained in SAOS method. For the Clue solutions,

the minimum $(\mathrm{m})$ and maximum $(\mathrm{M})$ heat fluxes between the oil and the solution were, respectively, 2.5 and $11 \mathrm{~kW} \mathrm{~m}^{-2}$ and for the XG solutions, 4 and $8 \mathrm{~kW} \mathrm{~m}^{-2}$.

Table 6
Range of Reynolds, Dean, Prandtl and Helical numbers used for the glycerol solutions.

\begin{tabular}{|c|c|c|c|c|c|c|}
\hline \multicolumn{2}{|c|}{ Solutions of CMC \% (w/w) } & \multirow{2}{*}{$\frac{0.1}{546}$} & \multirow{2}{*}{$\begin{array}{l}0.2 \\
656\end{array}$} & \multirow{2}{*}{$\frac{0.3}{101}$} & \multirow{2}{*}{$\frac{0.4}{26}$} & \multirow{2}{*}{$\begin{array}{l}0.6 \\
41\end{array}$} \\
\hline $\operatorname{Re}_{\mathrm{g}}$ & $\mathrm{m}$ & & & & & \\
\hline & M & 2828 & 3004 & 1384 & 1035 & 536 \\
\hline \multirow[t]{2}{*}{$\operatorname{De}_{(g)}$} & $\mathrm{m}$ & 88 & 106 & 16 & 4 & 7 \\
\hline & M & 458 & 487 & 224 & 168 & 87 \\
\hline \multirow[t]{2}{*}{$\mathrm{Pe}$} & $\mathrm{m}$ & 10396 & 42355 & 26433 & 47848 & 10496 \\
\hline & M & 53270 & 106361 & 80063 & 79906 & 63566 \\
\hline \multirow[t]{2}{*}{$\mathrm{Gz}$} & $\mathrm{m}$ & 7.5 & 31 & 23 & 3.8 & 7.5 \\
\hline & M & 38 & 76 & 46 & 57 & 46 \\
\hline \multirow[t]{2}{*}{$r r_{(g)}$} & $\mathrm{m}$ & $1 \%$ & 30 & bi & \% & $11 y$ \\
\hline & M & 20 & 48 & 104 & 203 & 261 \\
\hline \multirow[t]{2}{*}{ Pr } & $\mathrm{m}$ & 21 & 62 & 114 & 169 & 292 \\
\hline & M & 24 & 85 & 208 & 445 & 643 \\
\hline \multirow[t]{2}{*}{ Wi } & $\mathrm{m}$ & 32 & 320 & 200 & 136 & 656 \\
\hline & M & 232 & 1176 & 1960 & 2744 & 4472 \\
\hline El & - & 0.1 & 0.4 & 1.6 & 3.3 & 8.8 \\
\hline
\end{tabular}

\begin{tabular}{lllllll}
\hline & & 78 & 59 & 43 & 36 & 25 \\
\hline $\mathrm{Re}$ & 91 & 195 & 423 & 547 & 1189 \\
& $\mathrm{~m}$ & 210 & 1553 & 2260 & 4557 & 6293 \\
$\mathrm{De}$ & $\mathrm{M}$ & 35 & 32 & 69 & 89 & 193 \\
& $\mathrm{~m}$ & 160 & 252 & 366 & 739 & 1020 \\
$\mathrm{Pr}$ & $\mathrm{M}$ & 353 & 75 & 20 & 14 & 10 \\
& $\mathrm{~m}$ & 32 & 22 & 16 \\
$\mathrm{He}$ & $\mathrm{M}$ & 35 & 32 & 69 & 89 & 124 \\
& $\mathrm{~m}$ & 34 & 257 & 366 & 739 & 1020 \\
\hline
\end{tabular}

Table 7

Ranges of generalized Reynolds, modified Dean, Péclet, Graetz, modified Prandtl, Prandtl used by Hsu and Patankar [19], Weissenberg and elasticity numbers for the CMC solutions. 
Table 8

Ranges of generalized Reynolds, modified Dean, Péclet, Graetz, modified Prandtl, Prandtl used by Hsu and Patankar [19], Weissenberg and elasticity numbers for the XG solutions.

\begin{tabular}{|c|c|c|c|}
\hline \multicolumn{2}{|c|}{ Solutions of XG \% (w/w) } & 0.1 & 0.2 \\
\hline \multirow{2}{*}{$\operatorname{Re}_{g}$} & $\mathrm{~m}$ & 369 & 351 \\
\hline & M & 1976 & 2191 \\
\hline \multirow[t]{2}{*}{$\operatorname{De}_{(g)}$} & $\mathrm{m}$ & 60 & 57 \\
\hline & M & 320 & 355 \\
\hline \multirow[t]{2}{*}{$\mathrm{Pe}$} & $\mathrm{m}$ & 10107 & 10274 \\
\hline & M & 36916 & 52251 \\
\hline \multirow[t]{2}{*}{$\mathrm{Gz}$} & $\mathrm{m}$ & 7 & 7 \\
\hline & M & 27 & 38 \\
\hline \multirow[t]{2}{*}{$\operatorname{Pr}(g)$} & $\mathrm{m}$ & 19 & 24 \\
\hline & M & 27 & 44 \\
\hline \multirow[t]{2}{*}{ Pr } & $\mathrm{m}$ & 49 & 81 \\
\hline & M & 72 & 177 \\
\hline \multirow[t]{2}{*}{$\mathrm{Wi}$} & $\mathrm{m}$ & 1000 & 1824 \\
\hline & M & 7080 & 19688 \\
\hline $\mathrm{El}$ & - & 3.6 & 9.8 \\
\hline
\end{tabular}

The mean temperature, between inlet and outlet, of the fluids flowing inside the coil ranged between 20 and $45^{\circ} \mathrm{C}$. The physical properties of the fluids were determined at the mean temperature. For the calculation of the generalized Reynolds number, $R_{\mathrm{g}}$, modified Prandtl number, $\operatorname{Pr}_{(\mathrm{g})}$, and Prandtl number, Pr, the viscometric viscosity was calculated at the mean temperature by the method of reeduced properties previously described:

I $\operatorname{Re}_{g}=\frac{d_{i}^{n} v^{2-n} \rho T_{\text {ref }}}{a_{T}^{n} K\left(\frac{1+3 n}{4 n}\right)^{n} 8^{n-1} T}$

which is a combination of Eqs. (6), (18), and (19);

$\operatorname{Pr}_{(g)}=\frac{C_{p}}{k_{f}} K\left(\frac{v}{d_{i}}\right)^{n-1}\left(\frac{3 n+1}{4 n}\right)^{n} 8^{n-1} a_{T}^{n} \frac{T}{T_{\text {ref }}}$

which is a combination of Eqs. (10), (18), and (19);

$$
\operatorname{Pr}^{*}=\frac{C_{p}}{k_{f}} K\left(\frac{v}{d_{i}}\right)^{n-1} a_{\mathrm{T}}^{n} \frac{T}{T_{\text {ref }}}
$$

which is a combination of Eqs. (11), (18), and (19) but without $\partial_{4 n}^{3 n p 1 P^{n-1}} 8$.

The dimensionless numbers presented in Tables $6-8$ were obtained from 350 different experiments.

\subsection{Calculation method for Nusselt number}

The energy balance equation to the fluid circulating inside the coil is:

$$
\dot{Q}=\dot{m} C_{p} \Delta T-\Delta P \dot{V}
$$

where $\mathrm{DPV}$ - is the heat power generated by friction.

In addition, the project equation to the heat transferred between the oil and the fluid circulating inside the coil is:

$$
\dot{Q}=U A \Delta T_{\text {ln }}
$$

Matching Eqs. (31) and (32) one obtains:

$$
\dot{m} C p(T s-T e)-\Delta P \dot{V}=U A \Delta T_{\mathrm{ln}}
$$

where $U$ is the overall coefficient of heat transfer between the oil and the fluid flowing inside the coil, $A$ the heat transfer area and $\mathrm{D} T_{\ln }$ the logarithmic mean temperature difference given by:

$$
\Delta T_{\mathrm{ln}}=\frac{\left(T_{a l l}-T_{e}\right)-\left(T_{\text {oil }}-T_{s}\right)}{\ln \frac{\left(T_{o i}-T_{e}\right)}{\left(T_{\text {oil }}-T_{s}\right)}}
$$

The measured values of the flow, pressure drop, oil temperature and inlet and outlet temperatures of the fluid flowing in the coil are required to determine the value of $U A$.
The overall resistance to the heat transferred between the oil and the fluid circulating inside the coil (1/UA), has three contributions:

$$
\frac{1}{U A}=\frac{1}{h o_{c} A_{0}}+\frac{x_{\text {copper }}}{k_{\text {copper }} A_{m \ln }}+\frac{1}{h i_{c} A_{i}}
$$

where $x_{\text {coil }}$ is the wall thickness of the tube coil, $k_{\text {copper }}$ the thermal conductivity of the copper, $A_{i}, A_{o}$ and $A_{m} \ln$ are, respectively, the internal, external and mean logarithmic areas of the tube, $h i_{c}$ the heat transfer film coefficient between the inner wall of the coil and the fluid flowing in the coil and $h o_{c}$ the heat transfer film coefficient between the oil and the outer wall of the coil.

The $h i_{c}$ data will be presented in the form of Nusselt number defined as

$$
\mathrm{Nu}_{\mathrm{c}}=\frac{h i_{c} d_{i}}{k_{f}}
$$

The fluid properties were determined at the mean temperature, $T_{m}$, between the temperature of the fluid at entrance, $T_{e}$, and exit, $T_{s}$, of the coil,

$$
T_{m}=\frac{T_{e}+T_{s}}{2}
$$

According to Nigam et al. [20], at the coil inlet, the velocity and temperature profiles are in development along a distance equal to 30 diameters of the tube, i.e. $1.8 \%$ of the total lepgth of the coil. This before stabilization, cyclic oscillations around the final state $\left(\mathrm{Ni}^{-}\right.$ gam et al. [20]). Along the experimental data treatment, these inlet effects were not consider, i.e., the values obtained are for hypothetic developed profiles from the inlet to the outlet of the coil.

\subsection{Uncertainty analysis of the results}

The relative uncertainties of the experimental $h i_{c}$ values for Newtonian and non-Newtonian fluids are presented in Table 9.

The values of the relative uncertainties are, in, accordance to the values reported in the literature, which are around of $25 \%$ (Coleman and Steele [29]). A further explanation is given in the Appendix.

\section{Results and discussion}

\subsection{Newtonian fluids}

To explain the Nusselt number data in helical coils, it should be stressed that for Newtonian fluids circulating in a straight tube, fully developed laminar flow and constant heat flux boundary condition, Nusselt number is 4.36 for Prandtl numbers greater than

Table 9

Relative uncertainties of experimental $h i_{c}$ for glycerol, CMC and XG solutions.

\begin{tabular}{lll}
\hline Solution concentration $(\%)(\mathrm{w} / \mathrm{w})$ & & Relative uncertainty $(\%)$ \\
\hline Glycerol & 78 & 13 \\
& 59 & 19 \\
& 43 & 21 \\
& 36 & 25 \\
CMC & 25 & 23 \\
& 0.1 & 27 \\
& 0.2 & 36 \\
& 0.3 & 39 \\
XG & 0.4 & 20 \\
& 0.6 & 22 \\
& 0.1 & 23 \\
& 0.2 & 20 \\
\hline
\end{tabular}


0.6 , while for constant wall temperature boundary condition, Nusselt number is 3.66 (Incropera and DeWitt [30]).

Fig. 8 shows Nusselt number experimental data for all the glycerol solutions $(78 \%, 59 \%, 43 \%, 36 \%$ and $25 \%(\mathrm{w} / \mathrm{w}))$ as a function of the Dean number. First of all, all the values are much higher than that in a straight tube; the mixture is higher, due to the Dean vortices and the heat flux transferred increases. The figure also shows an increase of the Nusselt number as the Dean number increases and, for a given Dean number, the Nusselt number also increases as the Prandtl number increases.

In the literature, several studies (Mori and Nakayama [3] Janssen and Hoogendoorn [12], refer the similarity between the results obtained with both boundary conditions: constant wall temperature and constant heat flux. Table 10 presents the mean and standard deviations, of the relative difference between the Nusselt numbers obtained in this study (constant wall temperature) and those obtained through expressions cited in the literature (the boundary conditions are there specified). Based on the mean and standard deviations, it is not evident an influence of the boundary condition on the Nusselt number.

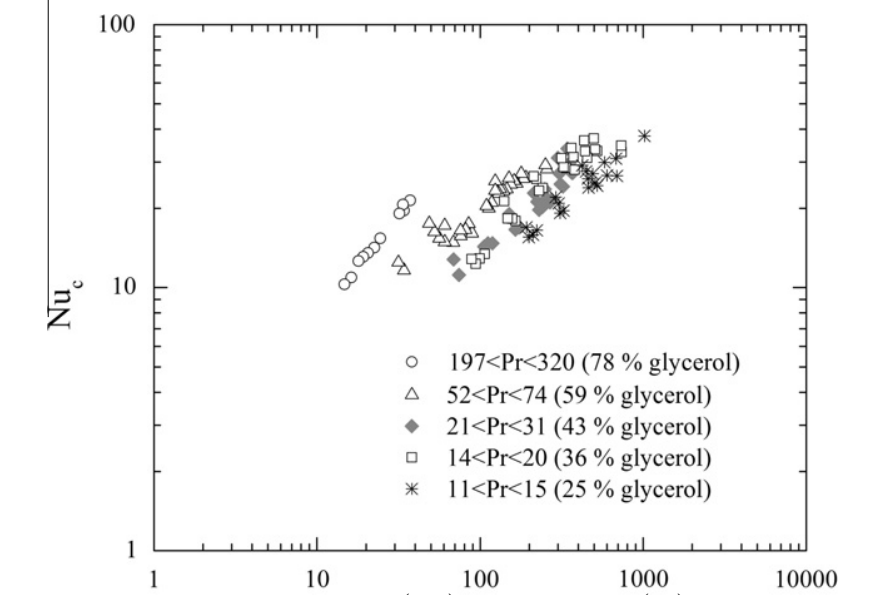

Fig. 8. Experimental Nusselt number $\left(\mathrm{Nu}_{c}\right) \mathrm{Ye}^{\text {Dean number }(\mathrm{De})}$ for all the glycerol solutions.

Table 10

Mean and standard deviation of the relative difference between experimental Nusselt number data for glycerol solutions and data from the correlations in the literature.

\begin{tabular}{|c|c|}
\hline & $\begin{array}{l}\text { Mean } \pm \text { standard } \\
\text { deviation }(\%)\end{array}$ \\
\hline $\begin{array}{l}\text { Mori and Nakayama [3] (constant wall temperature } \\
\text { and constant heat flux) }\end{array}$ & $51.8 \pm 20.0$ \\
\hline Schmidt [5] (constant wall temperature) & $23.9 \pm 21.7$ \\
\hline Dravid et al. [6] (constant heat flux) & $20.0 \pm 12.5$ \\
\hline Akiyama and Cheng [7] (constant heat flux) & $16.3 \pm 15.8$ \\
\hline Akiyama and Cheng [8] (constant wall temperature) & $34.1 \pm 21.0$ \\
\hline $\begin{array}{l}\text { Olivier and Asghar }[11](4<\mathrm{De}<60) \text { (constant wall } \\
\text { temperature) }\end{array}$ & $43.2 \pm 16.6$ \\
\hline $\begin{array}{l}\text { Olivier and Asghar }[11](60<\mathrm{De}<2000) \text { (constant wall } \\
\text { temperature) }\end{array}$ & $42.2 \pm 28.3$ \\
\hline $\begin{array}{l}\text { Janssen and Hoogendoorn }[12](\mathrm{De}<20) \text { (constant wall } \\
\text { temperature and heat flux) }\end{array}$ & $8.2 \pm 7.0$ \\
\hline $\begin{array}{l}\text { Janssen and Hoogendoorn }[12](20<\mathrm{De}<100) \\
\text { (constant wall temperature and heat flux) }\end{array}$ & $24.5 \pm 15.2$ \\
\hline $\begin{array}{l}\text { Janssen and Hoogendoorn }[12](100<\mathrm{De}<830) \\
(\text { constant wall temperature and heat flux })\end{array}$ & $12.0 \pm 12.3$ \\
\hline Manlapaz and Churchill [13] (constant heat flux) & $23.2 \pm 28.2$ \\
\hline $\begin{array}{l}\text { Manlapaz and Churchill [13] (constant wall } \\
\text { temperature) }\end{array}$ & $33.9 \pm 32.2$ \\
\hline Xin and Ebadian [14] (constant wall temperature) & $12.3 \pm 7.7$ \\
\hline
\end{tabular}

In Figs. 9 and 10, the experimental data are compared, respectively, with data from Janssen and Hoogendoorn [12] and from Xin and Ebadian [14].

The expression of Janssen and Hoogendoorn [12] (Fig. 9), for both constant wall temperature and constant heat flux, fits well the results of this work, with an average deviation of $15 \%$. However, the upper limit of the Dean number range (830) of Janssen and Hoogendoorn is lower than that in this study.

The experimental equation of Xin and Ebadian [14] (Fig. 10), is the one that better fits the experimental results of the present study. Xin and Ebadian worked at constant wall temperature, like we did. The validity conditions of the equation, regarding the range of the Dean number and curvature ratios, are also similar, but the upper limit of the Prandtl number is 175 while in this work is 353. In spite of this good concordance, and in order to compare Newtonian and non-Newtonian data, it was fitted to the experimental data of this work an equation with a similar functionality to that of Xin and Ebadian. The fitted equation is:

$$
\mathrm{Nu}_{\mathrm{c}}=\left(0.5 D e^{0.481}-0.465\right) \mathrm{Pr}^{0.367}
$$

This equation will be designated, from now on, by Modified Xin and Ebadian Correlation (MXEC) and is valid for laminar fully developed flow inside helical coils, for the boundary condition of constant wall temperature, and for $15<\operatorname{De}<1020,10<\operatorname{Pr}<353, d_{i} / d_{c}=0.0263$, $p=0.01134 \mathrm{~m}$ and $d_{i}=0.004575 \mathrm{~m}$.

It should be stressed that, the uncertainty of the experimental results, in the present work (Table 9) and in those from literature (most of the times not referred explicitly), can explain, and be responsible by the differences found between the results (Table 10).

\subsection{Non-Newtonian fluids}

To explain the results of the Nusselt numbers in helical coils, it should be stressed that for non-Newtonian fluids flowing in a straight tube, in fully developed laminar flow and constant heat flux boundary condition, the Nusselt number, $\mathrm{Nu}_{\mathrm{s}}$, can be obtained with the following theoretical expression (Pinho and Coelho [22]):

$$
\mathrm{Nu}_{s}=\frac{8(5 n+1)(3 n+1)}{31 n^{2}+12 n+1}
$$

This expression was obtained considering constant physical properties and purely viscous fluids following power law.

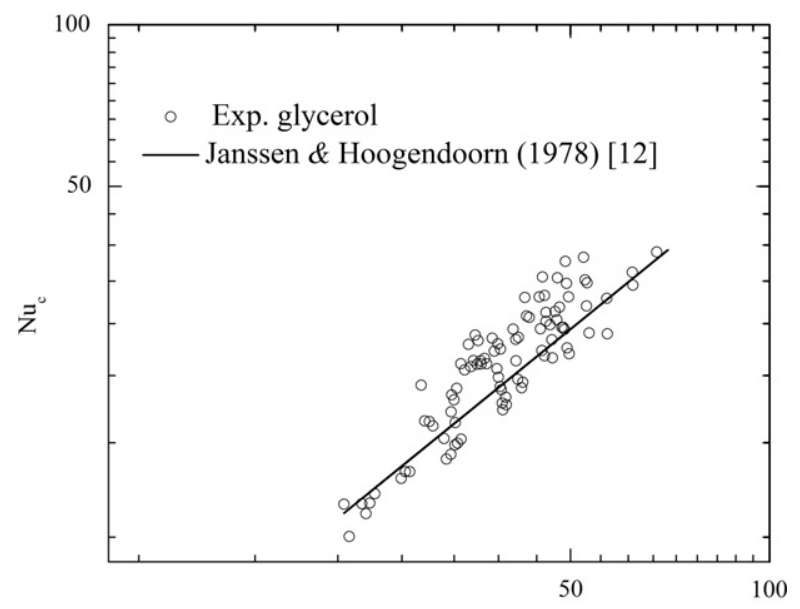

Fig. 9. Nusselt number $\left(\mathrm{Nu}_{c}\right)$ vs. $\operatorname{Re}^{0} \operatorname{R}^{3} \mathrm{Pr}^{0.42} \mathrm{Pr}_{-}^{1 / 6}$ comparison between data from glycerol experiments and data from Janssen and Hoogendoorn [12]). 


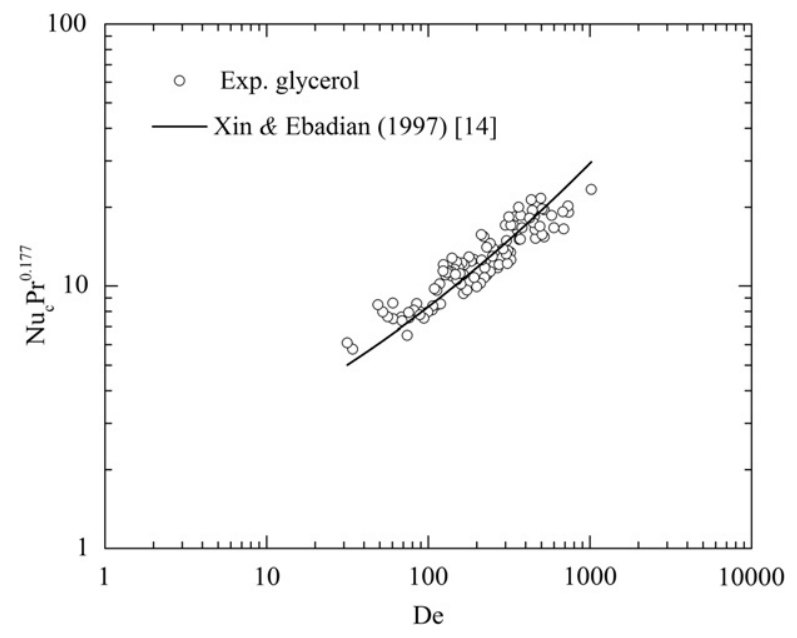

Fig. 10. Nusselt number $\left(\mathrm{Nu}_{\mathrm{c}}\right)$ vs. Dean number (De) - comparison between data from glycerol experiments and data from Xin and Ebadian [14]).

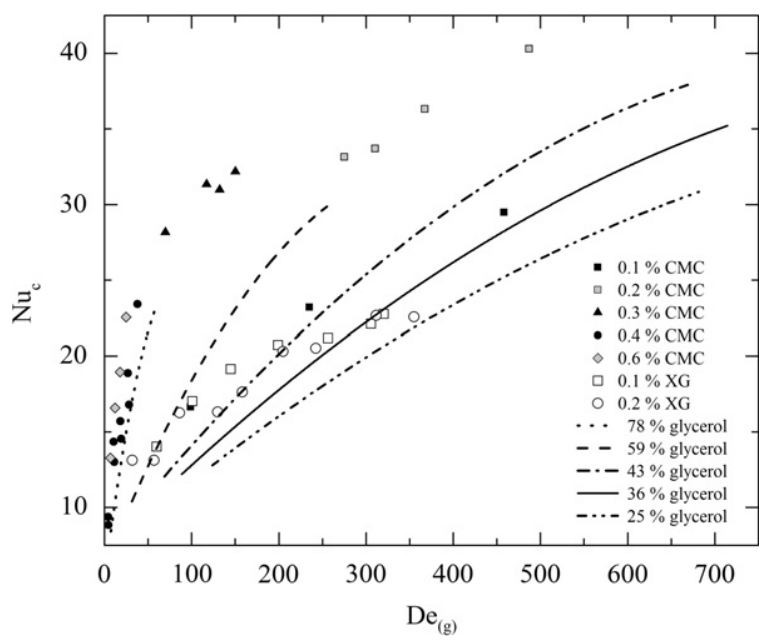

Fig. 11. Nusselt number $\left(\mathrm{Nu}_{\mathrm{c}}\right)$ vs. Dean number $(\mathrm{De}(\mathrm{g})$ for the non-Newtonian fluids CMC and XG experiments - comparison between experimental data and results obtained from correlation for glycerol solutions (MXEC).

For the condition of constant wall temperature, once more according to Pinho and Coelho [22], the values are 3.66, 3.95, 4.18 and 5.80 respectively for the behavior index of, $1,0.5,0.33$ and 0 .

For both boundary conditions, the greater is the behavior index, the lower is the Nusselt number. For a straight tube, the literature states that the results presented for both boundary conditions are valid either for purely viscous fluids as for viscoelastic fluids (Pinho and Coelho [22]).

Rajasekharan et al. [17,18], Olivier and Asghar [11], Hsu and Patankar [19] and Nigam et al. [20]) performed studies with nonNewtonian fluids, for similar conditions to those used in this work.
Hsu and Patankar [19] studied theoretically the heat transfer for fluids that follow the power law, for the boundary condition of constant heat flux. These authors found that for the same Dean number $\left(\mathrm{De}_{(\mathrm{g})}\right)$ and Prandtl number (Pr), the Nusselt numbers for shear thinning fluids are lower than those for Newtonian fluids. In order to confirm this statement, it was represented the Nusselt number as a function of the generalized Dean number, as shown in Fig. 11. The Nusselt numbers for the glycerol solutions were obtained from equation MXEC. It can be seen, with the help of $\mathrm{Ta}^{-}$ ble 11, that for the same ranges of Prandtl (Pr) and Dean $\left(\mathrm{De}_{(\mathrm{g})}\right)$ numbers, the Nusselt numbers of the solutions $0.1 \%, 0.2 \%, 0.3 \%$ and $0.4 \%$ of CMC are slightly higher than those of the Newtonian fluids. For the solution $0.6 \%$ of CMC, it is difficult to see the trend, because the upper limit of the Prandtl number is greater than the upper limit for the $78 \%$ glycerol solution. According to our results, it can be said that the higher velocity gradients near the tube wall, characteristic of the shear thinning fluids, potentiate the mixing effect promoted by the Dean cells.

The Nusselt numbers of the $0.1 \%$ and $0.2 \%$ XG solutions, for identical ranges of Dean $\left(\mathrm{De}_{(\mathrm{g})}\right)$ and Prandtl (Pr) numbers, are significantly lower than those of the glycerol solutions. This finding stresses the importance of the elasticity of the fluid, in the flow pattern, and, by consequence, in the heat transfer coefficients. The elasticity tends to overlap the viscous effect on the Nusselt number promoted by the shear thinning behavior. The degree of viscoelasticity of the fluids studied can be seen in Table 5, relaxation times, and in Tables 7 and 8, Weissenberg numbers.

Nigam et al. [20] studied, numerically, the heat transfer in shear thinning fluids in helical coils and obtained, as shown in Tables 1 and 2, Nusselt number values for Newtonian fluids similar to those of Hsu and Patankar [19] and for shear thinning fluids values slightly lower than those related in [19]. For the shear thinning fluids, the results of Nigam are close to those obtained in this work despite the fact that they are slightly lower than those for Newtonian fluids (Tables 1 and 2).

Fig. 12 shows the experimental results of Nusselt number as a function of the Graetz number (includes the product between Reynolds and Prandtl numbers), obtained with the aqueous solutions of CMC and XG and also the data from Rajasekharan et al. [18].The CMC solutions data of the present study are slightly higher, for the same Graetz number, than those given by the expression of Rajasekharan et al. [17,18]. However the functionality is very similar, i.e., the Graetz number seems to be the correct, and unique, dimensionless number that affects the Nusselt number for shear thinning fluids (geometric numbers are not in study). The experimental data for $0.2 \%$ XG solution are lower, for the same Graetz number and seems to follow a different correlation, i.e., once more, the elastic component seems to affect the heat transfer coefficient.

Fig. 13 shows the Nusselt experimental results and the data

from Olivier and Asghar [11] as function of $\mathrm{GZ}^{0.33}\left(1+a\left(\mathrm{De}^{+}\right)^{b}\right)$ $\left(d / d_{w}\right)^{0.14}$ - the coefficients $a$ and $b$ are in Table 2 . The fit equation of Olivier and Asghar [11] was obtained performing experiments with a viscoelastic solution, PAA. The results are lower than those of this work, especially for the CMC solutions. However, the values for the $0.2 \% \mathrm{XG}$ solution seem to follow the trend of Olivier and Asghar' equation.

Table 11

Mean and standard deviation of - Prandtl, modified Prandtl and Prandtl used by Hsu and Patankar [19] numbers for the glycerol, CMC and XG solutions.

\begin{tabular}{|c|c|c|c|c|c|c|}
\hline \multirow[t]{2}{*}{$\operatorname{Pr}$} & Solutions of glycerol \% (w/w) & 78 & 59 & 43 & 36 & 25 \\
\hline & Mean \pm standard deviation & $278 \pm 59$ & $61 \pm 10$ & $28 \pm 3$ & $19 \pm 2$ & $14 \pm 1$ \\
\hline \multirow[t]{2}{*}{ Pr } & Solutions of CMC \% (w/w) & 0.1 & 0.2 & 0.3 & 0.4 & 0.6 \\
\hline & Mean \pm standard deviation & $23 \pm 1.2$ & $71 \pm 6.2$ & $145 \pm 27$ & $238 \pm 71$ & $403 \pm 102$ \\
\hline \multirow[t]{2}{*}{ Pr } & Solutions of XG \% (w/w) & 0.1 & 0.2 & & & \\
\hline & Mean \pm standard deviation & $58 \pm 8$ & $116 \pm 32$ & & & \\
\hline
\end{tabular}




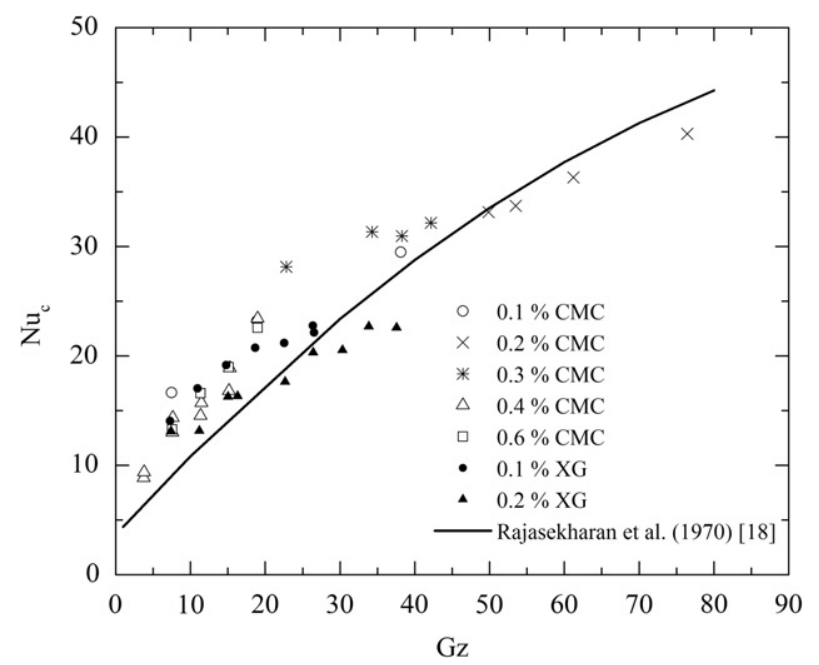

Fig. 12. Nusselt number $\left(\mathrm{Nu}_{\mathrm{c}}\right)$ vs. Graetz number $(\mathrm{Gz})$ for non-Newtonian fluids (CMC and $\mathrm{XG}$ ) experiments - comparison between experimental data and results from Rajasekharan et al. [18]).

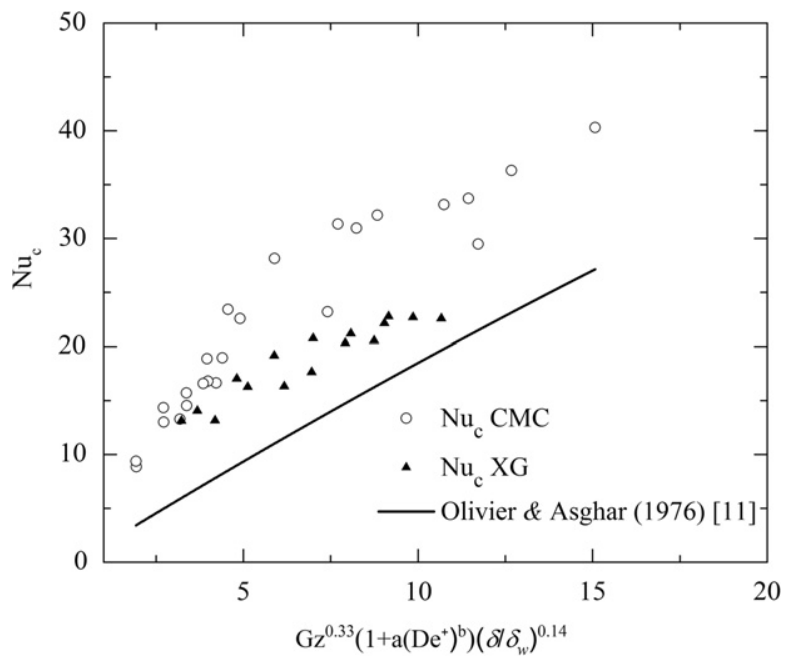

Fig. 13. Nusselt number $\left(\mathrm{Nu}_{c}\right)$ vs. $\mathrm{GZ}^{0.33}\left(1+a\left(\mathrm{De}^{+}\right)^{b}\right)\left(d / d_{w}\right)^{0.14}$ data for nonNewtonian fluids CMC and XG experiments - comparison between experimental data and results obtained from Olivier and Asghar [11]).

Table 12 shows the mean and the standard deviation of the relative difference between the experimental Nusselt number data, for CMC and XG solutions, and data from Rajasekharan et al. [18] and from Olivier and Asghar [11] respectively.

The average uncertainty of the results for non-Newtonian fluids varied, as can be seen in Table 9 , between $20 \%$ and $39 \%$. This uncertainty is not very high for experimental work concerning heat transfer, but may turn difficult the comparison with data from literature.

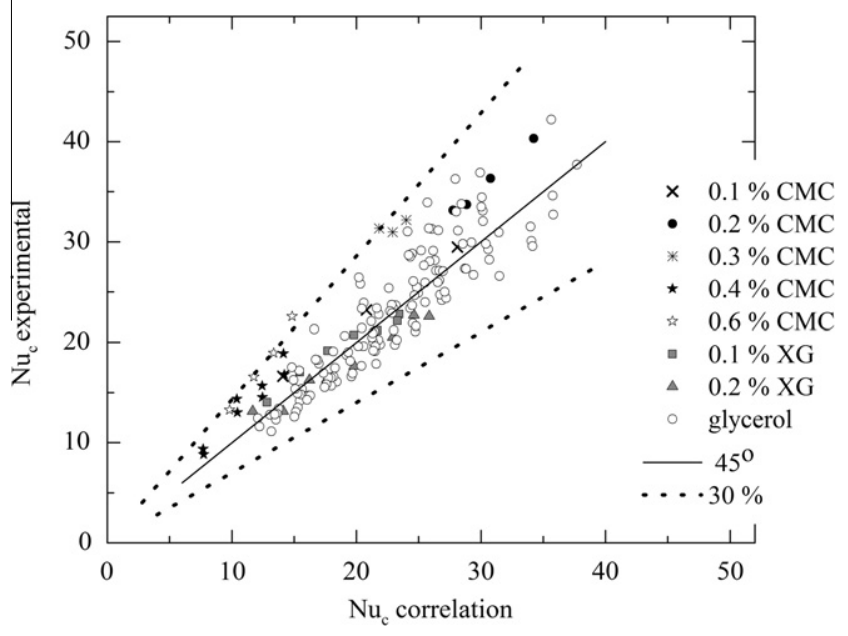

Fig. 14. Experimental Nusselt number vs. Nusselt number obtained with Eq. (39) for glycerol, CMC and XG solutions and lines of deviation of $30 \%$ and line of $45^{\circ}$.

A correlation, in some way based in that of Olivier and Asghar [11], was fitted to the experimental data of the present work. This correlation, Eq. (40), expresses the dependence of Nusselt number in Dean and Péclet numbers and also in Weissenberg number.

$$
\begin{aligned}
\mathrm{Nu}_{\mathrm{c}}= & 0.486\left[\left(\frac{3 n+1}{4 n}\right)^{0.275 n}\left(0.717+0.993 \frac{d_{i}}{d_{c}}\right) \mathrm{Pe}^{0.275}\right] \\
& \times\left(1+0.728 \mathrm{De}_{(\mathrm{g})}^{0.225}\right)(\mathrm{Wi}+1)^{0.011(n-1)}
\end{aligned}
$$

This equation is valid for constant wall temperature and was obtain in the following conditions: glycerol solutions $(15<\mathrm{De}<1020$, $10<\operatorname{Pr}<352$ ); CMC and XG solutions with index behavior between 0.34 and $0.90\left(4<\operatorname{De}_{(\mathrm{g})}<487,17<\operatorname{Pr}_{(\mathrm{g})}<203,32<\mathrm{Wi}<19700\right)$; $d_{i} / d_{c}=0.0263, p=0.01134 \mathrm{~m}$ and $d_{i}=0.004575 \mathrm{~m}$. The accuracy of the fit equation can be seen in Figure 14 where are represented the experimental results and data from Eq. (40). The maximum relative deviation is about $30 \%$, a value of the order of the maximum experimental error.

\section{Conclusions}

To calculate the Nusselt number for Newtonian fluids flowing in a helical coil, one can use, with accuracy, the correlation of Janssen and Hoogendoorn [12], valid for boundary conditions of constant heat flux and constant wall temperature and also that of Xin and Ebadian [14] valid for constant wall temperature.

From the data obtained with non-Newtonian fluids flowing in a helical coil with constant wall temperature, the most important conclusions are:

- Nusselt numbers of the CMC solutions (shear thinning fluids with low elastic component) were reasonably well represented by the correlation of Rajasekharan et al. [18];

\begin{tabular}{|c|c|c|c|c|c|c|}
\hline \multirow[b]{2}{*}{ CMC solution concentration (\%) (w/w) } & & \multicolumn{5}{|c|}{ Mean \pm standard deviation (\%) } \\
\hline & & 0.1 & 0.2 & 0.3 & 0.4 & 0.6 \\
\hline \multirow{5}{*}{ XG solution concentration $(\%)(w / w)$} & Rajasekharan et al. [18] & $38 \pm 27$ & $4 \pm 4$ & $13 \pm 6$ & $34 \pm 14$ & $32 \pm 5$ \\
\hline & Olivier and Asghar [11] & $56 \pm 21$ & $46 \pm 6$ & $70 \pm 5$ & $86 \pm 6$ & $82 \pm 3$ \\
\hline & & 0.1 & 0.2 & & & \\
\hline & Rajasekharan et al. [18] & $21 \pm 17$ & $16 \pm 11$ & & & \\
\hline & Olivier and Asghar [11] & $44 \pm 17$ & $23 \pm 21$ & & & \\
\hline
\end{tabular}

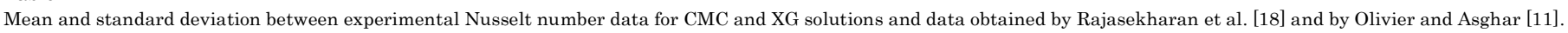


- Nusselt numbers of the CMC solutions were, on average, slightly higher than those of the Newtonian fluids for the same Prandtl, Pr, and generalized Dean numbers, $\mathrm{De}_{(\mathrm{g})}$;

- the viscous component of this shear thinning polymer tends to potentiate the mixing effect of the Dean cells;

- Nusselt numbers of the XG solutions, fluid with elastic behavior, are significantly lower than those of the Newtonian solutions, same Prandtl, Pr, and generalized Dean numbers, De(g);

- the elastic component of the polymer tends to diminish the mixing effect of the Dean cells.

A global correlation for Nusselt number as a function of Péclet, generalized Dean and Weissenberg numbers, for all Newtonian and non-Newtonian solutions studied is presented (Eq. (40)).

\section{Acknowledgment}

The authors acknowledge the support in this work of Eng. Víctor Ferreira, Dr. Adélio Cavadas and Dr. Paulo Coelho.

\section{Appendix - Uncertainty analysis of heat transfer film} coefficient between the inner wall of the coil and the fluid flowing in the coil

The equation to obtain the uncertainty of a result, with a confidence level of $95 \%$ and assuming that there are no correlated bias and precision errors [29], is:

$$
(U(R))^{2}=(B(R))^{2}+(P(R))^{2}
$$

where $U(R), B(R)$ e $P(R)$ are, respectively, the total uncertainty (or uncertainty), the bias error and the precision error associated to the calculation of the result $(R)$.

If the reduction equation to obtain a given experimental result is:

$R=R\left(X_{1}, X_{2} \ldots X_{j}\right)$

where $X_{j}$ are the variables whose uncertainty contributes to the uncertainty of the result, then the uncertainty of the result, is given by:

$$
\begin{aligned}
(U(R))^{2}= & \left(\frac{\partial[R]}{\partial X_{1}} U\left(X_{1}\right)\right)^{2}+\left(\frac{\partial[R]}{\partial X_{2}} U\left(X_{2}\right)\right)^{2}+\ldots \ldots \\
& +\left(\frac{\partial[R]}{\partial X_{j}} U\left(X_{j}\right)\right)^{2}
\end{aligned}
$$

The reduction equation of the heat transfer film coefficient between the inner wall of the coil and the fluid flowing in the coil, $h i_{c}$, is:

$$
h i_{c}=\frac{U A k_{\infty p p p e r} A_{m \ln } h o_{c} A_{o}}{\left(k A_{m} \ln h o_{c} A_{o} A_{i}-x_{c o l} A_{i} U A h o_{c} A_{o}\right) A_{o}-A_{i} k A_{m \ln } U A}
$$

The equation which allows the calculus of the uncertainty of the respective result, $U\left(h i_{c}\right)$, is:

$$
\begin{aligned}
\left(U\left(h i_{c}\right)\right)^{2}= & \left(\frac{\partial\left[h i_{c}\right]}{\partial A_{0}} U\left(A_{0}\right)\right)^{2}+\left(\frac{\partial\left[h i_{c}\right]}{\partial A_{i}} U\left(A_{i}\right)\right)^{2} \\
& +\left(\frac{\partial\left[h i_{c}\right]}{\partial A_{m} \ln } U\left(A_{m} \ln \right)\right)^{2}+\left(\frac{\partial\left[h i_{c}\right]}{\partial x} U\left(x_{\text {coul }}\right)\right)^{2} \\
& +\left(\frac{\partial\left[h i_{c}\right]}{\partial k} U\left(k_{\text {copper }}\right)\right)^{2}+\left(\frac{\partial\left[h i_{c}\right]}{\partial h o_{c}} U\left(h o_{c}\right)\right)^{2} \\
& +\left(\frac{\partial\left[h i_{c}\right]}{\partial(U A)} U(U A)\right)^{2}
\end{aligned}
$$

It is assumed that the uncertainty of the $k_{\text {copper }}$ was negligible in relation to the others uncertainties.
The values of the relative uncertainties associated to the heat transfer film coefficients between the inner wall of the coil and the fluids, $h i_{c}$, are shown in Table 9 . The method of calculating of the relative uncertainties of $h i_{c}$ is described in Eqs. sections A 1, A 2 and A 3.

\section{A 1 - Uncertainties of external, internal and mean logarithmic lateral areas and thickness of the coil}

The reduction equations for the calculation of the uncertainties of $A_{o}, A_{i}, A_{m \ln }$ and $x_{\text {coil }}$ are:

$$
\begin{aligned}
& A_{0}=2 \pi \frac{d_{o}}{2} L_{\text {coll }} \\
& A_{i}=2 \pi \frac{d_{i}}{2} L_{\text {coll }} \\
& A_{m \ln }=\frac{\pi L_{\text {col }}\left(d_{o}-d_{i}\right)}{\ln \frac{d_{o}}{d_{i}}} \\
& x_{\text {call }}=\frac{d_{o}-d_{i}}{2}
\end{aligned}
$$

The corresponding uncertainties are given by:

$$
\begin{aligned}
& \left(U\left(A_{0}\right)\right)^{2}=\left(\frac{\partial\left[\left(A_{0}\right)\right]}{\partial d_{o}} U\left(d_{o}\right)\right)^{2}+\left(\frac{\partial\left[\left(A_{0}\right)\right]}{\partial L_{\text {coil }}} U\left(L_{\text {coil }}\right)\right)^{2} \\
& \left(U\left(A_{i}\right)\right)^{2}=\left(\frac{\partial\left[\left(A_{i}\right)\right]}{\partial d_{i}} U\left(d_{i}\right)\right)^{2}+\left(\frac{\partial\left[\left(A_{i}\right)\right]}{\partial L_{\text {coil }}} U\left(L_{\text {call }}\right)\right) \\
& \left(U\left(A_{m \ln }\right)\right)^{2}=\left(\frac{\partial\left[\left(A_{m \ln }\right)\right]}{\partial d_{o}} U\left(d_{o}\right)\right)^{2}+\left(\frac{\partial\left[\left(A_{m \ln }\right)\right]}{\partial L_{\text {coll }}} U\left(L_{\text {coil }}\right)\right)^{2} \\
& +\left(\frac{\partial\left[\left(A_{m \ln }\right)\right]}{\partial d_{i}} U\left(d_{i}\right)\right)^{2} \\
& \left(U\left(x_{\text {cabre }}\right)\right)^{2}=\left(\frac{\partial\left[\left(x_{\text {cail }}\right)\right]}{\partial d_{o}} U\left(d_{o}\right)\right)^{2}+\left(\frac{\partial\left[\left(x_{\text {coll }}\right)\right]}{\partial d_{i}} U\left(d_{i}\right)\right)^{2}
\end{aligned}
$$

$U\left(d_{0}\right), U\left(L_{\text {coil }}\right)$ and $U\left(d_{i}\right)$ uncertainty values are in Table 3. Table A1 shows the values of the relative uncertainties of $A_{0}, A_{i}$,

\section{A 2 - Uncertainty associated to the heat transfer film coefficient between the oil and the outer wall of the coil, $U\left(h o_{c}\right)$}

The reduction equation for the calculation of the uncertainty associated to $h o_{c}=f\left(T_{o i l}\right)$ is:

$$
h o_{c}=\frac{(U A)_{h a_{c}} k_{c o p p e r} A_{m \ln }}{\left(k_{\text {copper }} A_{m \ln }-(U A)_{h o_{c}} X_{\text {coll }}\right) A_{o}}
$$

where, $\partial U A \mathrm{P}_{h o c}$ is the global heat transfer coefficient from the oil to the water in the coil times the lateral area of the coil.

Table A1

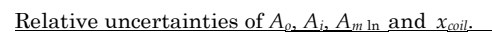

\begin{tabular}{ll} 
Variable & Relative uncertainty $(\%)$ \\
\hline$A_{o}$ & 0.8 \\
$A_{i}$ & 1.1 \\
$A_{m \ln }$ & 0.7 \\
$x_{\text {coil }}$ & 3.9 \\
\hline
\end{tabular}


The equation for the calculation of the uncertainty $U\left(h o_{c}\right)$ is:

$$
\begin{aligned}
& \left(U\left(h o_{c}\right)\right)^{2}=\left(\frac{\partial\left[h 0_{\varepsilon}\right]}{\partial(U A)_{h \omega_{\varepsilon}}} U\left((U A)_{h \omega_{\varepsilon}}\right)\right)^{2}+\left(\frac{\partial\left[h 0_{\varepsilon}\right]}{\partial k} U\left(k_{\text {coper }}\right)\right)^{2} \\
& +\left(\frac{\partial\left[h o_{c}\right]}{\partial A_{0}} U\left(A_{0}\right)\right)^{2}+\left(\frac{\partial\left[h o_{c}\right]}{\partial A_{m i n}} U\left(A_{m \text { in }}\right)\right)^{2} \\
& +\left(\frac{\partial\left[h_{\varepsilon}\right]}{\partial x} U\left(x_{\infty i}\right)\right)^{2}+(P(L))^{2}
\end{aligned}
$$

wnere $r(L)$ is tne precision error associated witn tne innear regression of $h o_{c}=f\left(T_{o i l}\right)$.

It is assumed that the uncertainty of the $k_{\text {copper }}$ was negligible in relation to the other uncertainties. The uncertainties of $A_{o}, A_{m \ln }$ and $x_{\text {coil }}$ have been calculated in Section A 1 . The uncertainties of the remaining variables are described in A 2.1 and A 2.2. The maximum relative uncertainty of $h o_{c}=f\left(T_{o i l}\right)$ is $4.76 \%$.

\section{A 2.1 - Uncertainty $U$ ¿UA ${ }_{h o}$}

In this case the fluid flowing in the coil was water. The reduction equation for the calculation of the uncertainty $U$ OUAP $h_{c}$ is:

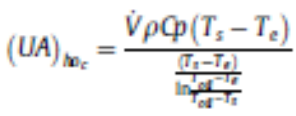

iment UððUAP ${ }_{h o_{c}}$ ' is:

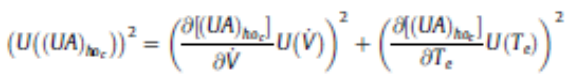

$$
\begin{aligned}
& +\left(\frac{\partial\left[(U A)_{h_{0}}\right]}{\partial T_{s}} U\left(T_{s}\right)\right)^{2} \\
& +\left(\frac{\partial\left[(U A)_{h \omega_{c}}\right]}{\partial T_{a d}} U\left(T_{a d}\right)\right)^{2} \\
& +\left(\frac{\partial\left[(U A)_{\text {serper }}\right]}{\partial \rho} U(\rho)\right)^{2}
\end{aligned}
$$

It is assumed that the uncertainty of $q$ was negligible in relation to the other uncertainties.

The relative uncertainty of $\partial U A \mathrm{P}_{h o_{c}}$ is $3.56 \%$ and the method of calculating is described in A 2.1.1 and A.1.2.

\section{A 2.1.1 - Bias error}

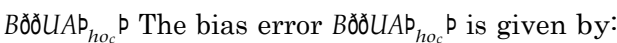

$$
\begin{aligned}
& \left(B\left((U A)_{h_{\text {ha }}}\right)\right)^{2}=\left(\frac{\partial\left[(U A)_{h_{e}}\right]}{\partial \dot{V}} B(\dot{V})\right)^{2}+\left(\frac{\partial(U A)_{h_{\text {ha }}}}{\partial T_{e}} B\left(T_{e}\right)\right)^{2} \\
& +\left(\frac{\partial\left[(U A)_{\text {hat }}\right]}{\partial T_{s}} B\left(T_{s}\right)\right)^{2} \\
& +\left(\frac{\partial\left[(U A)_{\text {tax }}\right]}{\partial T_{\text {all }}} B\left(T_{\text {oll }}\right)\right)^{2}
\end{aligned}
$$

The flowmeter bias error was provided by the manufacturer and its value is $1.2 \%$ of the read value.The general equation for the calculation of the bias errors of the temperatures $B\left(T_{s}\right), B\left(T_{e}\right)$ and $\left.B\left(T_{\text {oil }}\right)\right)$ is:

$$
\frac{B(T)}{T}=\left[\left(\frac{B(A / D)}{V_{c a d \text { max }}}\right)^{2}+\left(\frac{B\left(T_{\text {meds }}\right)}{T}\right)^{2}\right]^{0.5}
$$

where $B(A / D)$ and $B\left(T_{\text {meter }}\right)$ are, respectively, the data acquisition system and temperature meter bias errors.
The data acquisition system was composed by an analogic/digital board (A/D) with 14 bits of resolution and with $V_{c a l m a x}$ of $0.8 \mathrm{~V}$. According to Coleman and Steele [29], the signal digitalization uncertainty is equal to half of the least bit with significance (LSB) ( $1 \mathrm{LSB}=10 / 2^{c}$, where $c$ is the bits number). The bias error of the temperature measurement equipment $\left(T_{\text {meter }}\right)$ was considered equal to $0.4 \%$ of the read value, according to the manufacturer specifications.

Asan example, it is presented the calculations for the temperature of the oil at $80{ }^{\circ} \mathrm{C}$.

$$
\begin{aligned}
& B(A / D)=\frac{1}{2} \times \frac{10}{2^{14}}=3.05 \times 10^{-4} \mathrm{~V} \\
& B\left(T_{\text {mas }}\right)=0.004 \times 80=0.32^{\circ} \mathrm{C} \\
& \frac{B\left(T_{\text {oll }}\right)}{T_{\text {of }}}=\left[\left(\frac{3.05 \times 10^{-4}}{0.8}\right)^{2}+\left(\frac{0.32}{T_{\text {oll }}}\right)^{2}\right]^{0,5}
\end{aligned}
$$

$$
\text { A } 2.12 \text { - Precision error } P\left((U A)_{\text {ha }}\right)
$$

For a given experiment the precision error, $P(U A)_{\text {atu }}$, given by Eq. (A 23), is related to the variability of the volumetric flow rate.

$$
\left(P\left((U A)_{h 0_{c}}\right)\right)^{2}=\left(\frac{\partial\left((U A)_{h a_{k}}\right]}{\partial \dot{V}} P(\dot{V})\right)^{2}
$$

where $P(V)$ is the precision error of the volumetric flow rate.

For a given experiment, the precision error of the volumetric flow rate is given by:

$$
P(\dot{V})=t_{s} \frac{S_{\dot{V}}}{\sqrt{N}}
$$

where $S_{V-}$ is the volumetric flow rate standard deviation, $N$ is the number of readings of the volumetric flow rate $(N=60)$ and $t_{s}$ is the $t$ student distribution.

\section{A 2.2 - Precision error of linear regression}

The precision error $(P(L))$ of the linear regression of the function $h o_{c}=f\left(T_{o i}\right)$ is given by:

$$
P(L)=\left[\frac{\sum_{l-1}^{N}\left(h a_{e, 1}-\left(a T_{a l, 1}-b\right)\right)^{2}}{N-2}\right]^{0.5}
$$

where $a, e, b$ are, respectively, the slope of the line and the value of $h o_{c}$ when $T_{o i l}$ is zero and $N(=12)$ is the number of experiments (number of points in the linear regression).

\section{A 3 - Uncertainty of the heat transfer coefficient from the oil to the fluid in the coil times the lateral area of the coil, U(UA)}

In this case the fluids flowing in the coil are the solutions of glycerol, $\mathrm{CMC}$ and $\mathrm{XG}$. The reduction equation for the calculation of the uncertainty is:

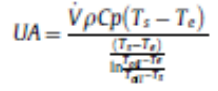

The equation to calculate the uncertainty $U U A$ is: 
Table A2

Uncertainities of UA for the glycerol solutions.

\begin{tabular}{ll}
\hline $\begin{array}{l}\text { Glycerol solutions } \\
(\%)(w / w)\end{array}$ & U(UA)/UA $(\%)$ \\
\hline 78 & 2.4 \\
59 & 2.2 \\
43 & 2.4 \\
36 & 2.2 \\
25 & 2.1 \\
\hline
\end{tabular}

Table A3

Uncertainities of $U A$ for the CMC

solutions.

\begin{tabular}{ll}
\hline $\begin{array}{l}\text { CMC solutions } \\
(\%)(w / w)\end{array}$ & U(UA)/UA (\%) \\
\hline 0.1 & 1.9 \\
0.2 & 2.4 \\
0.3 & 2.2 \\
0.4 & 2.0 \\
0.6 & 1.8 \\
\hline
\end{tabular}

Table A4

Uncertainities of UA for the XG solutions.

\begin{tabular}{ll}
$\begin{array}{l}\text { XG solutions } \\
(\%)(w / w)\end{array}$ & $U(U A) / U A(\%)$ \\
\hline 0.1 & 2.26 \\
0.2 & 2.2 \\
\hline
\end{tabular}

$$
\begin{aligned}
(U(U A))^{2}= & \left(\frac{\partial[U A]}{\partial \dot{V}} U(\dot{V})\right)^{2}+\left(\frac{\partial[U A]}{\partial T_{e}} U\left(T_{e}\right)\right)^{2} \\
& +\left(\frac{\partial[U A]}{\partial T_{s}} U\left(T_{s}\right)\right)^{2}+\left(\frac{\partial[U A]}{\partial T_{\alpha l l}} U\left(T_{\alpha L}\right)\right)^{2} \\
& +\left(\frac{\partial[U A]}{\partial \rho} U(\rho)\right)^{2}
\end{aligned}
$$

It is assumed that the uncertainty of $q$ was negligible in relation to the others uncertainties.

Tables A2-A4 show the uncertainties of $U A$ for glycerol, CMC and XG solutions for all experimental conditions. The method to calculate these values is described in A 3.1 and A 3.2 .

\section{A 3.1 - Bias error B(UA)}

The bias error of $U A(B(U A))$ is given by:

$$
\begin{aligned}
(B(U A))^{2}= & \left(\frac{\partial[U A]}{\partial \dot{V}} B(\dot{V})\right)^{2}+\left(\frac{\partial[U A]}{\partial T_{e}} B\left(T_{e}\right)\right)^{2} \\
& +\left(\frac{\partial[U A]}{\partial T_{s}} B\left(T_{s}\right)\right)^{2}+\left(\frac{\partial[U A]}{\partial T_{o t}} B\left(T_{\alpha a t}\right)^{2}\right.
\end{aligned}
$$

The method to calculate these bias errors is identical to that described in A 2.1.1.

\section{A 3.2 - Precision error $P(U A)$}

The precision error of $U A(P(U A))$ is given by:

$$
\begin{aligned}
(P(U A))^{2}= & \left(\frac{\partial[U A]}{\partial \dot{V}} P(\dot{V})\right)^{2}+\left(\frac{\partial[U A]}{\partial T e} P\left(T_{e}\right)\right)^{2} \\
& +\left(\frac{\partial[U A]}{\partial T S} P\left(T_{s}\right)\right)^{2}+\left(\frac{\partial[U A]}{\partial T^{\prime} \text { oleo }} P\left(T_{a l}\right)\right)^{2}
\end{aligned}
$$

The mean values of each of the variables in Eq. (A 29) are the result of two hundred experiments performed in steady state. So, it is necessary to calculate the precision error of each variable. The method to calculate them is described in A 2.1.2. The procedure involved was carried out for all the working fluids and for different experimental conditions (oil temperature and volumetric flow rate).

\section{References}

[1] W.R. Dean, The stream-line motion of fluid in a curved pipe, Philos. Mag. 5 (1928) 673-695.

[2] Y. Mori, W. Nakayama, Study on forced convective heat transfer in curved pipes - laminar region, Int. J. Heat Mass Transfer 8 (1965) 67-82.

[3] Y. Mori, W. Nakayama, Study on forced convective heat transfer in curved pipes - theoretical analysis under the condition of uniform wall temperature and practical formulae, Int. J. Heat Mass Transfer 10 (5) (1967) 681-695.

[4] Y. Mori, W. Nakayama, Study on forced convective heat transfer in curved pipes - turbulent region, Int. J. Heat Mass Transfer 10 (5) (1967) 37-59.

[5] E.F. Schmidt, Heat transfer and pressure loss in spiral tubes, Chem.-Ing.-Tech. 39 (1967) 781.

[6] A.N. Dravid, K.A. Smith, E.W. Merrill, P.L.T. Brian, Effect of secondary fluid motion on laminar flow heat transfer in helically coiled tubes, AIChE J. 17 (5) (1971) 1114

[7] M. Akiyama, K.C. Cheng, Boundary vorticity method for laminar forced convection heat transfer in curves pipes, Int. J. Heat Mass Transfer 14 (10) (1971) 1659

[8] M. Akiyama, K.C. Cheng, Laminar forced convection heat transfer in curved pipes with uniform wall temperature, Int. J. Heat Mass Transfer 15 (7) (1972) 1426.

[9] J.M. Tarbell, M.R. Samuels, Momentum and heat transfer in helical coils, Chem. Eng. J. 5 (1973) 117-127.

[10] C.E. Kalb, J.D. Seader, Fully developed viscous-flow heat-transfer in curved circular tubes with uniform wall temperature, AIChE J. 20 (2) (1974) 340-346.

[11] D.R. Olivier, S.M. Asghar, Heat transfer in Newtonian and viscoelastic liquids during laminar flow in helical coils, Trans. Inst. Chem. Eng. 54 (1976) 218-224.

[12] L.A.M. Janssen, C.J. Hoogendoorn, Laminar convective heat transfer in helical coiled tubes, Int. J. Heat Mass Transfer 21 (9) (1978) 1197-1206.

[13] R.L. Manlapaz, S.W Churchill, Fully-develpged laminar convection from a

[14] R.C. Xin, M.A. Ebadian, The effects of Prandtl numbers on local and average convective heat transfer characteristics in helical pipes, J. Heat Transfer 119 (1997) $467-473$

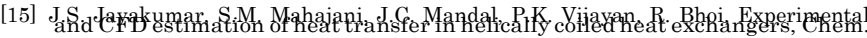
Eng. Res. Des. 86 (3) (2008) 221-232.

[16] J.S. Jayakumar, S.M. Mahajani, J.C. Mandal, K.N. Iyer, P.K. Vijayan, CFD analysis of single-phase flows inside helically coiled tubes, Comput. Chem. Eng. 34 (4) (2010) 430-446.

[17] S. Rajasekharan, V. Kubair, N.R. Kuloor, Secondary flow of nonNewtonian fluids in helical coils, Ind. J. Technol. 4 (2) (1966) 33-35.

[18] S. Rajasekharan, V.G. Kubair, N.R. Kuloor, Heat transfer to non-Newtonian fluids in coiled pipes in laminar flow, Int. J. Heat Mass Transfer 13 (10) (1970) $1583-1594$.

[19] C.F. Hsu, S.V. Patankar, Analysis of laminar non-Newtonian flow and heattransfer in curved pipes, AIChE J. 28 (4) (1982) 610-616.

[20] K.D.P. Nigam, S. Agarwal, V.K. Srivastava, Laminar convection of nonNewtonian fluids in the thermal entrance region of coiled circular tubes, Chem. Eng. J. 84 (2001) 223-237.

[21] A.B. Metzner, J.C. Reed, Flow of non-Newtonian fluids - correlation of the laminar, transition turbulent-flow regions, AIChE J. 1 (4) (1955) 434-440.

[22] F.T. Pinho, P.M. Coelho, Non-Newtonian heat transfer in rheology, in: Crispulo Gallegos (Ed.), Encyclopedia of Life Support Systems (EOLSS), Developed under the Auspices of the UNESCO, Eolss Publishers, Oxford, UK, 2009. Chapter 17.

[23] W.M. Rohsemow Y.I Cho J.P. Hartnett, Handbook of Heat Transfer, third ed.,

[24] N. Semmar, J.L. Tanguier, M.O. Rigo, Analytical expressions of specific heat capacities for aqueous solutions of CMC and CPE, Thermochim. Acta 419 (2004) 51-58.

[25] R.B. Bird, R.C. Armstrong, O. Hassager, Dynamics of Polymeric Liquids, Fluid Mechanics, second ed., John Wiley and Sons, 1987.

[26] P.M. Coelho, F.T. Pinho, Vortex shedding in cylinder flow of shear thinning fluids I. Identification and demarcation of flow regimes, J. Non-Newton. Fluid Mech. 110 (2-3) (2003) 143-176.

[27] A.S. Cavadas, F.T. Pinho, J.B.L.M. Campos, Laminar non-Newtonian impinging jet flow confined by sloping plane walls, J. Nonnewton. Fluid Mech. 169-170 (2012) 1-14.

[28] H. Ito, Laminar flow in curved pipes, Z. Angew. Math. Mech. 49 (11) (1969) 653.

[29] H.W. Coleman, W.G. Steele, in: Experimentation and Uncertainty Analysis for Engineers, second ed., John Wiley and Sons, 1999.

[30] F.P. Incropera, D.P. DeWitt, Fundamentals of Heat and Mass Transfer, fifth ed., Wiley, 2001. 